\title{
Vascular Smooth Muscle Cells Mechanosensitive Regulators and Vascular Remodeling
}

\author{
Shangmin Liu ${ }^{a, b} \quad$ Zhanyi Lin ${ }^{a, c}$ \\ a Ji Hua Institute of Biomedical Engineering Technology, Ji Hua Laboratory, Foshan, China; b Medical Research Center, \\ Guangdong Academy of Medical Sciences, Guangdong General Hospital, Guangzhou, China; Institute of Geriatric \\ Medicine, Guangdong Academy of Medical Sciences, Guangdong General Hospital, Guangzhou, China
}

\author{
Keywords \\ Circumferential stress - Vascular smooth muscle cells . \\ Mechanosensitive $\cdot$ Vascular remodeling
}

\begin{abstract}
Blood vessels are subjected to mechanical loads of pressure and flow, inducing smooth muscle circumferential and endothelial shear stresses. The perception and response of vascular tissue and living cells to these stresses and the microenvironment they are exposed to are critical to their function and survival. These mechanical stimuli not only cause morphological changes in cells and vessel walls but also can interfere with biochemical homeostasis, leading to vascular remodeling and dysfunction. However, the mechanisms underlying how these stimuli affect tissue and cellular function, including mechanical stimulation-induced biochemical signaling and mechanical transduction that relies on cytoskeletal integrity, are unclear. This review focuses on signaling pathways that regulate multiple biochemical processes in vascular mesangial smooth muscle cells in response to circumferential stress and are involved in mechanosensitive regulatory molecules in response to mechanotransduction, including ion channels, membrane receptors, integrins, cytoskeletal proteins, nuclear structures, and cascades. Mecha-
\end{abstract}

noactivation of these signaling pathways is closely associated with vascular remodeling in physiological or pathophysiological states.

(c) 2021 S. Karger AG, Base

\section{Introduction}

The perception and response of living cells and tissues to mechanical forces and the microenvironment they are exposed to are essential for their survival and functional maintenance [1, 2]. Fung et al. [3] put forward the "stressgrowth" theory in 1990, pointing out that the remodeling process of living tissue, including cell growth and extracellular matrix (ECM) production and absorption, is closely related to the stress state in the tissue.

Stress regulates almost all aspects of cellular function, including growth, differentiation, migration, gene expression, protein synthesis, and apoptosis, and also directly affects tissue morphology and function [4]. For example, mechanical stress plays a crucial role in regulating the normal development, structure, and function of blood vessels [5]. During the embryonic period, the undifferentiated and immature vascular network (precursor vascular plexus) gradually forms a stratified vascular system

Correspondence to:

Zhanyi Lin, linzhanyi@gdph.org.cn 
consisting of arteries and veins [6,7], in which blood pressure can affect the differentiation of mesenchymal cells into vascular smooth muscle cells (VSMCs), resulting in structural differences between arteries and veins [8, 9]. Such structural differences can also have a differential impact on the progression of vascular disease later in life. For example, veins do not usually develop atherosclerotic disease. However, when an autologous superficial saphenous vein is used as a conduit for arterial reconstruction during cardiac or limb bypass surgery, the arterialized vein is subjected to relatively high arterial pressure and is more likely to develop atherosclerotic disease, ultimately leading to vein graft failure $[10,11]$. This demonstrates that the mechanical forces to which a blood vessel is subjected are critical to its structure and function. In adulthood, normal blood pressure is also essential for maintaining vascular structure and function, and the pulsatile nature of blood pressure generates radial and tangential forces, mainly in the form of cyclic stretch and shear flow, which have a sustained effect on the vessel wall composition, such that hypertension leads to arterial wall thickening and stiffness increased $[12,13]$. Friction between blood and the vessel wall generates fluid shear stresses parallel to the vascular surface, which act mainly on the endothelial cells (ECs) at the blood vessel wall junction [14]; circumferential stresses are perpendicular to the vessel wall and act on all cells in the vessel wall $[15,16]$.

VSMCs, located in the middle layer of blood vessel, are the most numerous cell types in the arteries. VSMCs have 2 phenotypes: contractile and synthetic. Contractile VSMCs are mature, with a high degree of differentiation, poor proliferation and migration ability, and low synthetic activity. Synthetic VSMCs have few inner myofilaments and have strong synthesis and secretion functions; they mainly synthesize and secrete matrix proteins [17]. During blood vessel formation, the phenotype of VSMCs in the middle wall changes, which reduces ECM protein secretion and increases intracellular sarcoplasm formation. This transition, from synthesis to contraction, maintains the elasticity of the vascular wall and contracts blood vessels $[17,18]$. Under pathological conditions, cells in mature blood vessels can undergo a transition from a normal contraction state to a proliferative synthetic state $[19,20]$. Under normal circumstances, the morphology, structure, and function of VSMCs change, which causes VSMCs to proliferate and migrate excessively, accompanied by different degrees of aging, apoptosis, and other biological phenomena. This process is called the phenotypic transformation of VSMCs, also known as dedifferentiation [19]. When VSMCs are removed from their native envi-

VSMC Mechanosensitive Regulators and

Vascular Remodeling ronment and placed in vitro, similar changes in the cell phenotype can be observed. This is probably due to the lack of normal physiological signals in the blood vessel walls to maintain and regulate the VSMC phenotype [18]. The VSMC phenotype is a continuum, not a set of discrete phenotypic states [18]. VSMCs play a key role in maintaining vascular homeostasis and regulating pathological vascular remodeling in response to circumferential stress.

To study the effect of circumferential stress stimulation on VSMCs, in vitro mechanical loading systems are often used to circularly stretch the VSMCs to simulate the circumferential stress in vivo, generally with a loading rate of $10 \%-20 \%$ of the mechanical deformation as the overload group and $2 \%-5 \%$ of the mechanical deformation as the normal control group or with $100-200 \mathrm{kPa}$ as the overload group and $50 \mathrm{kPa}$ as the normal control group. In vivo, the hypertension model is used. The model uses blood pressure as a variable to compare the differences in the phenotype and biochemical function of VSMCs under hypertension and normal blood pressure. In an in vitro vascular culture system with independent control of arterial circumferential and shear stresses [21], carotid arteries were cultured under a circumferential stress of 50 or $150 \mathrm{kPa}$ and a shear stress of 0.75 or $2.25 \mathrm{~Pa}$ for 3 days. The results showed that matrix synthesis, SMC proliferation, and cell death significantly increased under high circumferential stress, while high shear had no significant effect on cell proliferation and expression of biomarkers of remodeling [21]. Circumferential wall stress is also a mechanism for arteriolar rarefaction and proliferation in a network model [22]. VSMCs can regulate proliferation, apoptosis, and migration, as well as ECM synthesis, degradation, and reorganization, by responding to circumferential stress. This review discusses how VSMCs sense such mechanical stimuli and undergo mechanical signaling to influence gene expression and regulate cellular function, with a focus on the studies of VSMCs in the midvascular layer responding to circumferential circulatory mechanical stimuli and regulating multiple mechanosensitive pathways that are further involved in the development of cardiovascular diseases (CVDs), such as hypertension.

\section{Mechanosensitive Mechanisms and Their Role in VSMCs}

The correct regulation of cellular function in vivo requires the integration of numerous biological and mechanical signals generated by the surrounding cells and the ECM, the complex mechanical behavior of tissues and 
the ECM, leading to cellular mechanotransduction and affecting cell behavior [23]. VSMCs sense mechanical stimuli and through cell-ECM interactions can affect the protein conformation of the cell membrane, where ion channels, membrane receptors, or transmembrane proteins play a central role in mechanical transduction and trigger downstream signaling cascades leading to forcedependent changes in gene expression [24]. Cells interacting with the ECM in a mechanical manner can also mediate a network of coordinated changes in integrins, connexin, cytoskeleton proteins, and nuclear structure to achieve mechanosignal transduction (Fig. 1); this mechanosignal propagates much faster in the cytoplasm than diffusion-based chemical signals $[25,26]$.

\section{Mechanosensive Molecules on Cell Membranes \\ Mechanosensitive Ion Channels}

Mechanosensitive ion channels are a class of cation channels that are affected by mechanical stress and generate excitatory electrical signals. These channels are involved in the mechanical transduction of cells, converting mechanical signals on the cell membrane into bioelectrical signals. VSMCs subjected to mechanical stress exhibit transient increases and depolarization of intracellular cations, affecting their own proliferation and migration, maintaining smooth muscle tone, and participating in cardiovascular mechanobiology, such as vascular development and blood pressure regulation, and related clinical diseases $[18,27]$.

Fig. 1. Circumferential stress-induced signaling pathway in VSMCs. Circumferential stress activates transmembrane proteins such as mechanosensitive ion channels (including Piezo1, TRP, $\mathrm{K} 2 \mathrm{P}$, and $\mathrm{ENaC}$ ), GPCRs, and RTK, integrins, FAK, cell junction (cadherin-11), cytoskeleton, and nuclear protein (lamin and emerin). Multiple downstream signaling pathways would be then activated simultaneously, inducing the expression and repression of multiple genes and leading to many cellular effects. The MAPK, Rho, Hippo signaling pathways, ER stress, and small-molecule gas signaling molecules are involved in these processes. These effects would lead to vascular remodeling, such as hypertension, pulmonary hypertension, and grafted venous atherosclerosis, and the same principle can be applied to the construction of bioengineered blood vessels. ECM, extracellular matrix; Piezo1, pressuresensitive protein Piezo ion channels; TRP, transient receptor potentials; K2P, 2-pore-domain potassium channel; ENaC, epithelial sodium channel; GPCRs, G protein-coupled receptors; RTK, receptor tyrosine kinases; TGII, transglutaminase II; ATF6, activating transcription factor 6; Klf2, Kruppel-like factor 2; IRE1 $\alpha$, inositol-requiring enzyme 1 $\alpha$; Notch, Notch protein; PTEN, phosphatase and tension homolog; YAP1, Yes-associated protein
Piezo Ion Channels. Piezo1 ion channels are mechanically activated nonselective cation channels. Piezol was identified in mouse neuroblastoma in 2010 and subsequently detected by sequence homology as the structurally and genetically similar protein Piezo2 [28]. When an external force is applied to the Piezo ion channel, the channel's spatial structure undergoes a reversible flattening effect in response to biological stress, which is important with regard to the sensing of mechanical stimuli [29]. Piezo1 and Piezo2 act as force sensors, pivotal in the determination and maintenance of cardiovascular architecture and function [30]. Piezo1 is expressed in ECs and VSMCs and is activated by shear stress associated with increased local blood flow and by stretching of the cell membrane in response to increased blood pressure [31].

Piezol is required for regulating NO formation, vascular tone, and blood pressure [32]. In ECs, Piezo1 can mediate fluid-shear-stress-induced release of adrenomedullin, which increases cyclic adenosine monophosphate (cAMP) levels, promoting endothelial nitric oxide synthase phosphorylation through protein kinase $\mathrm{A}$ and regulating vascular tone and blood pressure [33]. Endothelial Piezol also mediates flow-induced ATP release and subsequent P2Y2/Gq/G11-dependent activation of downstream signaling that induces protein kinase $\mathrm{B}$ (Akt) and endothelial nitric oxide synthase phosphorylation and activation, thus regulating vascular tone and blood pressure $[32,34]$. Shear-stress-induced Piezo1 confers force sensitivity on ADAM10 and Notch1, with downstream consequences for sustained activation of Notch1

1; MEK, mitogen-activated protein kinase; MAPK, mitogen-activated protein kinases; ERK, extracellular regulated protein kinase; JNK, c-Jun N-terminal kinases; P38, P38 MAPK; HIF-1a, hypoxia-inducible factor-1 $\alpha, \mathrm{G}, \mathrm{G}$ protein; PI3K, phosphatidylinositol-3 kinases; Akt, protein kinase B; PKA, protein kinase A; PLC, phospholipase C; PKC, protein kinase C; PIP2, phosphatidylinositol 4,5-bisphosphate; Ras, a family of small GTPase; Raf, RAF kinases; MMPs, matrix metalloproteinases; mTOR, mammalian target of rapamycin; Src, sarcoma; FAK, focal adhesion kinase; Grb2, growth factor receptor-bound protein 2; PyK2, proline-rich tyrosine kinase 2; ILK, integrin-linked kinase; SPRR3, atheroma-enriched protein; Rho, the Ras super family of low molecular weight GTPases; ROCK, Rho-associated coiled coil-forming protein kinase; MLCP, myosin light-chain phosphatase; MHC, myosin heavy chain; iNOS, inducible nitric oxide synthase; NO, nitric oxide; Nox, NADPH oxidase; NF- $\kappa \mathrm{B}$, nuclear factor kappa-lightchain enhancer of activated B cells; SOCS-1, suppressor of cytokine signaling; TGF- $\beta$, transforming growth factor- $\beta$; AP- 1 , APETALA1; c- FOS, proto-oncogene c-fos gene; TCF, T-cell factor; $\mathrm{PAH}$, pulmonary arterial hypertension; VSMCs, vascular smooth muscle cells.

(For figure see next page.)
92

J Vasc Res 2022;59:90-113

DOI: $10.1159 / 000519845$
$\mathrm{Liu} / \mathrm{Lin}$ 
target genes [35]. However, under cyclic strain (15\% stretch; 60 cycles/min), Notch receptor signaling is inhibited in VSMCs [36]. When the fluid flow along the endothelial surface is high enough, depolarization increases, and Piezo1 in vascular ECs can activate the voltage-gated
$\mathrm{Ca}^{2+}$ channels in adjacent VSMCs, causing vasoconstriction, and is thereby involved in hypertension-dependent arterial remodeling [37, 38].

In SMCs, is the Notch signaling pathway responsive to mechanical stimulation associated with the mechanosen-

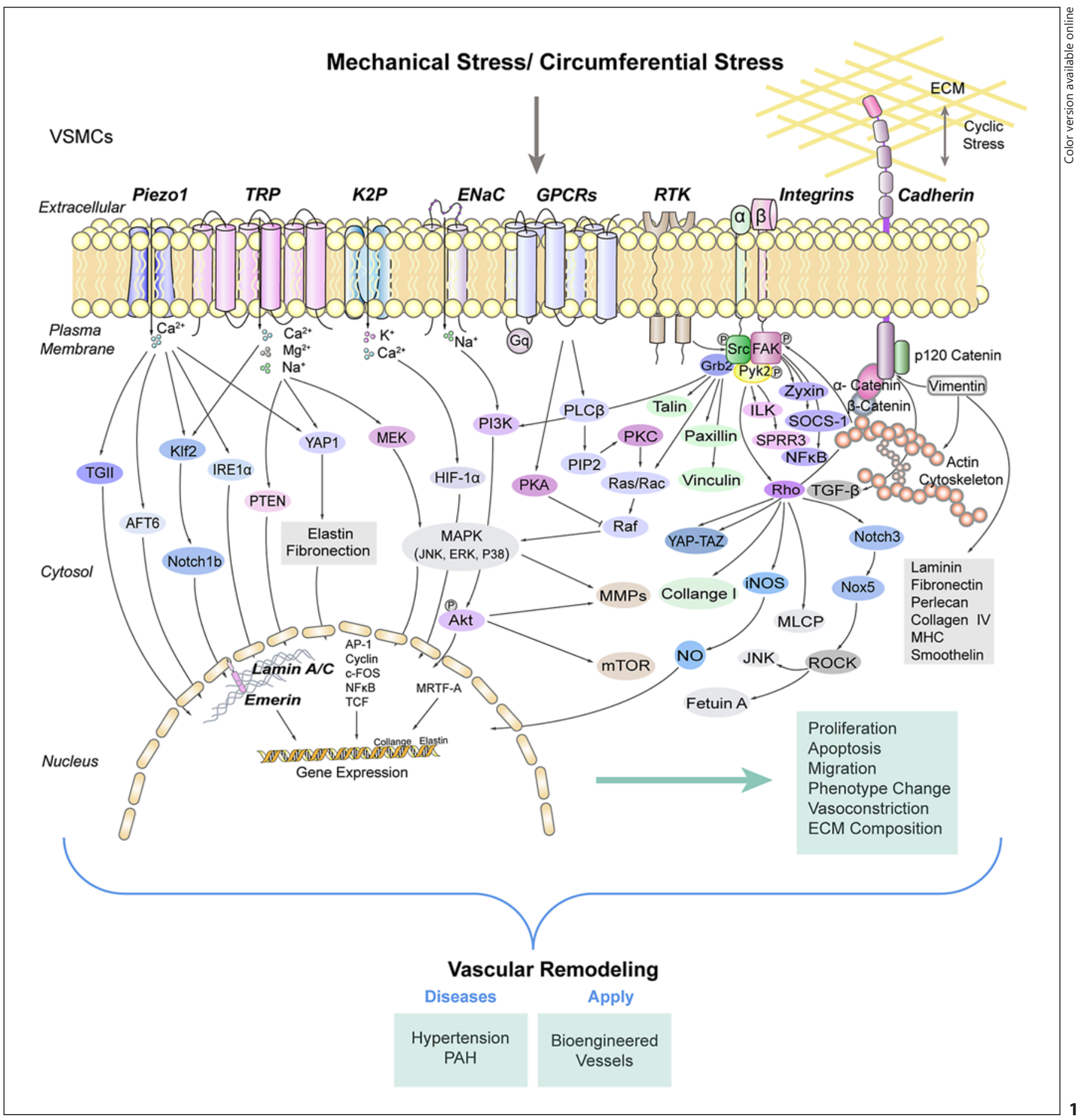

VSMC Mechanosensitive Regulators and 
sitive Piezo ion channel, and does it ultimately affect the biochemical function of SMCs through Piezo ion channel? Studies have confirmed that Piezol is indeed involved in the SMCs response to mechanical stimulation in vitro.

Piezo controls Klf2 and Notch activity in the endothelium and Yes-associated protein 1 (YAP1) localization in smooth muscle progenitors [39]. Piezol is a determinant of the vascular architecture during early development. Piezo1-deficient embryos are lethal due to disturbed vascular development $[40,41]$. Both Piezo1 and Piezo2 are required for normal pressure receptor function, and the use of fiber optic irradiation of the cervical sinus and vagus nerve to activate Piezo expression reduces heart rate and blood pressure, whereas dual failure of Piezo leads to unstable hypertension and blood pressure variability [42]. Piezo1 is also highly expressed in SMCs of smalldiameter arteries that are actively involved in the regulation of peripheral resistance, whereas it is more sparsely expressed in conduit arteries [31]. Under hypertensive conditions, opening of Piezo1 ion channels in SMCs induces an increase in vessel diameter and wall thickness, which is reversed by specific expression deficiency and completely inhibits stretch-activated ion channels [43]. Piezol ion channel opening increases $\mathrm{Ca}^{2+}$ concentrations in the cytoplasm of VSMCs, stimulates transglutaminase II activity, and is involved in cytoskeletal as well as ECM remodeling [43]. Mechanical stimulation of Piezo1 is also dependent on the interaction with ECM proteins, with the presence of some ECM proteins, leading to increased mechanical sensitivity of Piezol to membrane tension [44]. These studies illustrate a functional link between the opening of Piezol ion channels in VSMCs and clinically relevant arterial remodeling, and involvement in systemic hypertension.

Transient Receptor Potentials. The transient receptor potential (TRP) family of channel proteins consists of 4 TRP subunits in homo- or hetero-tetramers, which can be divided into 7 subclasses based on sequence similarity: TRPC, TRPV, TRPM, TRPA, TRPN, TRPP, and TRPML. Various forms of mechanical stimulation can activate or modulate certain TRP channel proteins, which are important stretch sensors in vascular smooth muscle [45].

TRPs exist in VSMCs and play an important role in the regulation of vasoconstriction. An increase in intraluminal pressure causes a gradual depolarization of VSMCs, which is linked to the opening of nonselective stretchactivated cation channels [46]. In COS-7 cells (an expression system for studying mechanically sensitive ion channels), the TRPP1/TRPP2 ratio regulates stretch-activated cation channel activity via the filamin A /F-actin cytoskeletal network and modulates the arterial myogenic response to intraluminal pressure [47]. In arterial SMCs, PKD2 (TRPP1) channels regulate systemic blood pressure, and SMC-specific PKD2 knockout can lower both physiological blood pressure and hypertension and prevent pathological arterial remodeling during hypertension [48]. Intravascular pressure (physiological pressure $80 \mathrm{~mm} \mathrm{Hg}$ ) regulates the surface density of SUMOPKD2-mediated Na currents in arterial SMCs (myocytes) to control arterial contractility [49]. The control group with arterial pressurization at low pressure $(10 \mathrm{~mm} \mathrm{Hg})$ led to a reduction in the surface SUMO-PKD2 protein to $\sim 42.4 \%$ of that in fresh-isolated $(0 \mathrm{~h})$ arteries [49].

In VSMCs, enhanced membrane stretch mediates elevated intracellular $\mathrm{Ca}^{2+}$ and $\mathrm{Na}^{+}$via activation of TRPC1, TRPC3, and TRPC6 channels, leading to VSMC dysfunction [50]; TRPC6 is required to transduce stress-induced vasoconstriction in the middle cerebral artery (MCA) of mice and is localized in cerebral VSMCs, and the pressure-induced vasoconstriction disappears in the MCA of TRPC6-knockout mice $[51,52]$. TRPC6 regulates the phenotype of VSMCs via a cell membrane potential with PTEN-dependent coupling [53]. In pulmonary artery SMCs (PASMCs) from pulmonary arterial hypertension (PAH) patients and animal PAH models, Notch signal enhances TRPC6 store-operated $\mathrm{Ca}^{2+}$ channels via direct (nongenomic and stimulatory) and indirect (genomic and upregulating) effects [54]. On the other hand, the activation of $\mathrm{Ca}^{2+}$-sensing receptors evokes $\mathrm{Ca}^{2+}$ influx through TRPC6 receptor-operated $\mathrm{Ca}^{2+}$ channels, and the athophysiological function of pulmonary aortic VSMCs is mediated by enhanced $\mathrm{Ca}^{2+}$ signaling via TRPC6 store-operated $\mathrm{Ca}^{2+}$ and receptor-operated $\mathrm{Ca}^{2+}$ channels during increased luminal pressure [54].

TRPV2 activation induces nonselective cation channel currents and elevated intracellular $\mathrm{Ca}^{2+}$, inducing myogenic contraction of SMCs [55]; TRPV4 activation induces $\mathrm{Ca}^{2+}$ inward flow and endoplasmic reticulum (ER) stress response, which plays an important role in vasoconstriction; TRPV4 is also a mechanosensor in preglomerular VSMCs, contributing to renal myogenic autoregulation, and blocking TRPV4 channels reverses the steady-state myogenic tone (MT) in preglomerular VSMCs and inhibiting pressure-induced membrane depolarization, $\mathrm{Ca}^{2+}$ elevation, and distal interlobular artery constriction [56]; TRPV4 channels maintain blood flowinduced vasodilation, preserve vascular function by directly activating $\mathrm{Ca}^{2+}$-dependent $\mathrm{K}^{+}-\mathrm{Ca}^{2+}$ channels [57], and indirectly induce vasodilation and maintain blood 
pressure by releasing $\mathrm{NO}$, also mediating hypoxia-induced increased proliferation and migration of PASMCs involved in the progression of PAH [58].

In human and Sprague-Dawley rat PASMCs with PAH, TRPM7 is downregulated, which activates the mitogenactivated extracellular signal-regulated kinase (MEK)/extracellular-signal-regulated kinase (ERK) pathway and decreases cellular $\mathrm{Mg}^{2+}$ levels, thus promoting SMC proliferation exacerbating PAH [59]. TRPML1 is crucial for the initiation of $\mathrm{Ca}^{2+}$ sparks in SMCs and the regulation of vascular contractility and blood pressure, and TRPML1knockout mice are spontaneously hypertensive [60].

Two-Pore-Domain Potassium Channel. The 2-poredomain potassium channel is an important type of cellular potassium channel protein family, which can be classified into 6 isoforms based on gene sequence conservation and channel functional properties: TWIK, TREK, TASK, TALK, THIK, and TRESK $[61,62]$. These proteins can be mechanically activated by the membrane stretch in heterologous expression systems or proteoliposomes, and they have a wide range of mechanical force sensing and a low response threshold $\left(0.5-12 \mathrm{mN} \cdot \mathrm{m}^{-1}\right)$; the stronger the mechanical force perceived, the higher the likelihood of channel opening [63, 64]. The membrane potential of VSMCs is a key regulator of vascular tone and therefore regulates flow and pressure in the circulation. The negative resting potential of VSMCs is low, between $\pm 40 \mathrm{mV}$ and $\pm 60 \mathrm{mV}$, but they are sensitive to changes in $\mathrm{K}^{+}$conductance [65], and 2-pore-domain potassium channels in smooth muscles are the components of myogenic regulation [66].

TREK- 1 channel activity is induced by increased membrane stretch and is independent of intracellular $\mathrm{Ca}^{2+}$ and ATP, and TREK-1 can respond to membrane stretch in intact cells as well as isolated plaques, demonstrating that the mechanical force can control the channel $[67,68]$. In spontaneously hypertensive rats (SHRs), high blood pressure significantly reduces both mRNA and protein expression levels of TASK-1 in aortic SMCs, affecting $\mathrm{K}^{+}$ conductance and the resting membrane potential and leading to vasoconstriction [69]. The TASK3(KCNK3) gene of the potassium channel is a susceptibility gene for $\mathrm{PAH}[70,71]$, and rats with mutations in the KCNK3 gene exhibit a marked ECM deposition in the distal pulmonary artery. In PASMCs of rats with mutations in this gene, the overall $\mathrm{K}^{+}$current is significantly reduced, enhancing vasoconstriction associated with PASMC membrane depolarization; meanwhile, KCNK3 knockdown or blockage can lead to increased hypoxia-inducible factor 1 -alpha expression and excessive proliferation of PASMCs

VSMC Mechanosensitive Regulators and

Vascular Remodeling
$[72,73]$. In PAH, the reduced expression of TASK5 in VSMCs affects SMC proliferation and migration, also causing pulmonary vasoconstriction $[70,74,75]$.

Epithelial Sodium Channel. The epithelial sodium channel (ENaC/DEG) superfamily of proteins are voltage-insensitive sodium-selective channels. $\mathrm{ENaC}$ can participate in the regulation of systemic blood pressure [76], and genetic mutations in humans cause gain-of-function/ loss-of-function in $\mathrm{ENaC}$, resulting in monogenic forms of hypertension/hypotension [77]. ENaC can respond to mechanical strain to promote cell differentiation [78]. VSMCs have $\alpha$-, $\beta$-, and $\gamma$-ENaC isoforms in the plasma membrane, and $\mathrm{ENaC}$ proteins are associated with vascular smooth muscle mechanotransduction [79-81].

Changes in extracellular sodium may alter myogenic responses by altering the sensitivity of smooth muscle mechanoreceptors to stretch. Increased extracellular sodium levels decrease MT [82]. $\beta$-ENaC is required for normal mechanically gated currents in renal VSMCs, and mice with reduced levels of $\beta$-epithelial $\mathrm{Na}^{+}$channels $\left(\beta-\mathrm{ENaC}^{\mathrm{m} / \mathrm{m}}\right)$ inhibit the myoconstrictor response in small renal arteries and afferent small arteries in response to myoconstriction [83]. Amiloride and benzamil are relatively high-affinity ENaC inhibitors that selectively inhibit $\mathrm{ENaC}$ channels, and low doses inhibit $\mathrm{ENaC}$ but do not inhibit other molecules such as the L-type $\mathrm{Ca}^{2+}$ channel, $\mathrm{Na}^{+}-\mathrm{H}^{+}$exchanger, $\mathrm{Na}^{+}-\mathrm{Ca}^{2+}$ exchanger, and TRP6, which inhibits pressure-mediated constriction of the MCA, the interlobular artery, and the small renal input artery [84]. Inhibition of $\mathrm{ENaC}$ by amiloride $(1 \mathrm{~mol} / \mathrm{L})$ and the amiloride analog benzamil $(30 \mathrm{nmol} / \mathrm{L}, 1 \mathrm{~mol})$ blocked pressure-mediated myogenic constriction of arteries in an isolated rat MAC model of distraction induction [84]. $\beta$ and $\gamma$-subunit ENaC are required for vascular mechanotransduction, and VSMCs from rat brain and mouse renal vessels transfected with $\beta$ - and $\gamma$-EnaC short interfering RNA inhibit pressure-induced myogenic contraction [85].

\section{G Protein-Coupled Receptors and G Proteins}

$G$ protein-coupled receptors (GPCRs) are 7 transmembrane helix proteins that transmit extracellular signals to cells, usually through conformational rearrangement of their helices and subsequent binding and activation of intracellular heterotrimeric [86, 87]. G proteins are a class of signaling proteins that bind guanosine diphosphate and have guanosine triphosphate (GTP) hydrolase activity. The signal transduction pathway in which $\mathrm{G}$ proteins are involved is a conserved transmembrane signal transduction mechanism. When cells transduce extracellular signals, they are first stimulated by dif- 
ferent types of GPCRs, which are then activated to further activate heterotrimeric $G$ proteins on the inner side of the plasma membrane; these heterotrimeric $G$ proteins in turn activate various effectors downstream of them to generate intracellular second messengers, thus transmitting the signal down the chain $[88,89]$.

GPCRs and $G$ proteins play an important role as mechanoreceptors [90], and the GPCR systems in VSMCs play a crucial role in vascular MT $[91,92]$. Myogenic vasoconstriction is an autoregulatory function of small arteries, which is essential for maintaining vascular tone, peripheral vascular resistance, and organ perfusion. Vascular MT requires a complex mechanical transduction that translates a physical stimulus (stress) into a biological response (change in vessel diameter) [93-95]. The different involvement of these GPCRs and G proteins in various vascular territories could allow selective targeting of the MT in a specific tissue or organ. Angiotensin II type 1 (AT1Rb) receptor as a type of GPCR [96] is the main sensor of intracellular pressure in the smooth muscle of cerebral arteries. Pressure- or membrane stretch-induced activation of $\mathrm{AT} 1 \mathrm{Rb}$ activates TRPM4 channels, leading to inward transient cationic currents that depolarize SMCs and cause vasoconstriction. The use of angiotensin II also activates $\mathrm{AT} 1 \mathrm{Ra}$ and AT1Rb to stimulate vasoconstriction in cerebral arteries [97]. Stretch activation of AT1Ra contributes to the myogenic response of mouse mesenteric and renal arteries through the coupling of the AT1Ra with a Gq/11 protein [98]. Membrane stretch leads to agonist-independent activation of $\mathrm{G}(\mathrm{q} / 11)$-coupled receptors, which subsequently signal to TRPC channels in a G protein- and phospholipase C-dependent manner [91]. Increasing the AT (1) angiotensin II receptor density in mechanically unresponsive rat aortic $\mathrm{A} 7 \mathrm{r} 5$ cells resulted in mechanosensitivity [91]. The MT of cerebral and renal arteries is significantly reduced by AT1R blockade; this inhibitory effect is enhanced in blood vessels of mice deficient in the regulator of $G$ protein signaling-2, which is a selective and negative regulator of $\mathrm{Gq} / 11$ proteins [99]. These findings suggest that $\mathrm{G}(\mathrm{q} / 11)$-coupled receptors function as sensors of membrane stretch in VSMCs $[91,100]$. The Gq/11 protein-coupled receptor signaling pathway induces vasoconstriction and hypertension, and the $\mathrm{Gq} / 11$ inhibitor ligand blocks vasoconstriction induced by multiple Gq-coupled receptors in resistance arterial SMCs [101]. With activation of Gq-11 and G12-13 proteins, Gq-11 cascades through phospholipase C- $\beta$ (PLC $\beta$ ) and G12-13 through Rho signaling pathway signaling $[92,102]$.

Another study reported that $\mathrm{AT}_{1 \mathrm{~A} / 1 \mathrm{~B}}{ }^{-1-}$ arteries exhibit a reduced MT at high intraluminal pressures $(>100 \mathrm{~mm}$
$\mathrm{Hg}$ ) but an unexpected increased MT at low pressures (20-70 mm Hg). At low intraluminal pressures, only cysteinyl leukotriene 1 receptors (CysLT1Rs) were significantly upregulated in $\mathrm{AT}_{1 \mathrm{~A} / 1 \mathrm{~B}}{ }^{-/-}$isolated murine mesenteric arteries [103]. The MT is determined by AT1 and CysLT1 receptors acting together as mechanosensors via Gq/11-protein activation [103]. CysLT1Rs can also mediate the contraction of bronchial smooth muscle [104].

Purinergic signaling plays an important role in vascular tone and remodeling, and activation of VSMC receptors promotes vasoconstriction via $\mathrm{P} 2 \mathrm{X} 1$ or pyrimidinesensitive P2Y receptors [105]. Purinergic P2Y6 receptor (P2Y6R), an inflammation-inducible GPCR, promotes Ang-II-induced hypertension in mice. Deletion of P2Y6R attenuates an Ang-II-induced increase in blood pressure, vascular remodeling, and oxidative stress. AT1R and P2Y6R form stable heterodimers, which enhances $G$ protein-dependent vascular hypertrophy but reduces $\beta$-arrestin-dependent AT1R internalization [106]. The increased abundance of P2Y6R converts AT1R-stimulated signaling in VSMCs from $\beta$-arrestin-dependent proliferation to $G$ protein-dependent hypertrophy [106]. P2Y6-receptor-knockout mice confirmed the involvement of these receptors in aortic-endothelium-dependent relaxation to uridine diphosphate and smooth muscle contraction to uridine diphosphate (and uridine triphosphate) [107]. In arterial SMCs, P2Y6 and P2Y2 receptors contribute to calcium mobilization; $\mathrm{P} 2 \mathrm{Y} 6$ activation is mandatory for Ras homolog family member A (RhoA)-GTP binding, myosin light chain (MLC), P42-P44, and c-Jun $\mathrm{N}$-terminal kinase phosphorylation; and $\mathrm{P} 2 \mathrm{Y} 6$ receptor blockade blunts the MT in mouse mesenteric resistance arteries and human subcutaneous arteries [108].

Mechanical stress activates AR and downstream signaling pathways, such as ERKs, and increases VSMC proliferation [109]. Protease-activated receptors (PARs) are also a class of GPCRs that are activated by specific serine proteases through protein hydrolysis of their $\mathrm{NH}_{2}$ termini, and mechanical stress upregulates PAR-1 expression in VSMCs $[110,111]$. PARs are involved in the development of atherosclerosis, and atherosclerosis improves in PAR2deficient mice $[112,113]$. In a mouse model of hypertension, GPR75 knockdown prevented elevated blood pressure, smooth muscle contraction, and vascular remodeling [114]. GPR68 senses flow and is essential for vascular physiology, and GPR68-deficient mice show marked acute flow-mediated dilation (FMD) impairment and chronic flow-mediated outward remodeling in small mesenteric arteries [115]. The mechanical stimulus mentioned in this paper is flow shear stress, which mainly acts on ECs instead
96

J Vasc Res 2022;59:90-113

DOI: $10.1159 / 000519845$
$\mathrm{Liu} / \mathrm{Lin}$ 
of directly on VSMCs, and MT is a property of SMCs and flow-mediated dilation a property of ECs. Some studies have characterized GPR68/OGR1 activation in VSMCs. In human aortic SMCs, GPR68 is a major receptor involved in the extracellular acid-induced stimulation of PGI (2) production and cAMP accumulation, which has been shown to be inhibitory for proliferation and migration [116]. Thus, in these acidic circumstances, GPR68 activation may be considered to counteract vasoconstriction and inflammation. In airway SMCs, GPR68 can activate multiple signaling pathways, involving $\mathrm{p} 42 / \mathrm{p} 44, \mathrm{PKB}, \mathrm{PKA}$, and calcium mobilization, which is the direct target and mediates airway smooth muscle contraction [117]. Extracellular acidification stimulates interleukin- 6 production and $\mathrm{Ca}^{2+}$ mobilization through proton-sensing OGR1 receptors/Gq-11 proteins in human airway SMCs [118], which induces connective tissue growth factor production, thereby inducing ECM protein formation and airway remodeling. In these studies, GPR68 was regarded as a proton-sensing receptor in SMCs, responding to the extracellular acidic environment and activating response signaling pathways to affect the proliferation and contraction of SMCs. However, whether GPR68 can directly respond to mechanical stimuli and conduct mechanotransduction in VSMCs remains to be further investigated. These results indicate that VSMCs can respond to mechanical signals via GPCRs and $G$ proteins on the cell membrane and perform a cascade response.

\section{Receptor Tyrosine Kinases}

Receptor tyrosine kinases (RTKs) are the largest class of enzyme-linked receptors, acting as both receptors and enzymes [119], and transmembrane proteins with intracellular kinase domain sites and extracellular domain sites [120], capable of binding to ligands and acting as receptors for a variety of growth factors, including epidermal growth factor (EGF), nerve growth factor, platelet-derived growth factor (PDGF), vascular endothelial growth factor, fibroblast growth factor, insulin, and insulin-like growth factor (IGF) $[121,122]$. Mechanical stress can nonspecifically activate RTKs, and the intracellular C-terminal kinase structural domain of activated RTKs phosphorylates its own tyrosine residues, resulting in binding sites for the Src homolog 2 (SH2) and phosphotyrosine-binding structural domains. Proteins containing $\mathrm{SH} 2$ or phosphotyrosine-binding structural domains bind to RTKs, so they are activated and signal to downstream factors [123-126].

Mechanical stretch increases matrix metalloproteinase-2 (MMP-2) production in VSMCs by activating the
PDGF receptor (PDGFR)- $\beta$ /Akt signaling pathway [127]. The stretch of VSMCs induces rapid PDGFRa phosphorylation and the effect depends on the stretch amplitude $[128,129]$. Cyclic strain activates PDGFR $\beta$, thus inducing mouse embryonic stem cell differentiation into VSMCs [130]. Mechanical stretch enhances insulin-induced VSMC proliferation by upregulating IGF-1 receptor and downstream Src/EGF receptor-mediated activation of ERK and Akt [131], and also stimulates and maintains tyrosine phosphorylation of IGF-1R and insulin receptor substrate 1 (IRS-1), leading to increased VSMC proliferation [132]. Mechanical stretch $(15 \%, 1 \mathrm{~Hz})$ significantly upregulates the protein expression of EGFR and mitogen-activated protein kinase (MAPK) phosphatase-1 in SHRs, promoting VSMC proliferation [133]. Cyclic stretch $(20 \%, 1 \mathrm{~Hz})$ also induces EGFR phosphorylation in rat VSMCs and interacts with the bridging protein (Shc/Grb2), leading to rapid phosphorylation activation of ERK1/2 and stimulation of SMCs growth [134]. These results suggest that RTKs on the VSMC surface play a role in the mechanosensing of stretch.

As described above, ion channels, membrane receptors, or transmembrane proteins on the cell membrane play a central role in mechanical signaling in SMCs and trigger downstream signaling cascades that lead to forcedependent changes in gene expression, affecting SMC proliferation, migration, phenotypic transition, and ECM synthesis.

\section{Integrins}

Integrins are a family of cell membrane surface protein receptors, heterodimers consisting of $\alpha$ - and $\beta$-subunits, that not only mediate the interconnection between cells and cells, the ECM, and the cytoskeleton but also act as signal receptors and are considered important transmitters of the conversion of mechanical forces into chemical signals $[135,136]$.

In response to mechanical stimulation, integrins can interact with the ECM and cytoskeleton and other signaling molecules [137, 138]. Integrins accumulate in focal adhesion, which can interact with a variety of proteins (Src, FAK, Talin, vinculin, and paxillin) to form focal adhesion complexes [139], and integrins activate signaling pathways, such as Rho GTPase and the MAPK pathway, which in turn produce a series of effects that convert mechanical signals into biochemical cascades $[140,141]$.

Integrin expression and activity are also affected by mechanical stimulation. In rat aortic SMCs, the expression of integrin $\alpha_{\mathrm{v}} \beta_{3}$ and the generation of thrombin on the surface of VSMCs increased by $30 \%$ without inducing 
apoptosis by cyclic stretch $(10 \%, 1 \mathrm{~Hz})$ during 60 and 360 min [142]; cyclic stretch also stimulated Src phosphorylation, talin cleavage, and prothrombin binding to VSMCs, whereas the integrin $\alpha_{\mathrm{v}} \beta_{3}$ antagonist peptide (cRGDPV) blocked the cyclic-stretch-induced $\alpha_{v} \beta_{3}$ expression, Src phosphorylation, and thrombin generation [142, 143]. In both human and mouse atherosclerotic lesion VSMCs, mechanical cyclic stretch $(15 \%-20 \%, 1 \mathrm{~Hz})$ activates integrin $\alpha_{1} \beta_{1}$, as well as upregulating SPRR3 expression, and integrin $\alpha_{1} \beta_{1}$ plays an essential role in cyclic stretchmediated SPRR 3 protein expression [144]. When VSMCs are exposed to progressively high stress, integrins convert mechanical stimuli into intracellular $\mathrm{Ca}^{2+}$ signaling events to mediate myogenic contractile responses in small arteries, promoting vasoconstriction [145].

Integrins are activated when the vascular mechanics microenvironment is altered, and enhanced mechanical force applied to integrin adhesion promotes smooth muscle proliferation. The integrin $\alpha_{\mathrm{v}} \beta_{3} / \mathrm{PI} 3-\mathrm{K} /$ Akt pathway mediates the proliferative and apoptotic responses of VSMCs $[142,146]$. Integrin $\alpha_{5} \beta_{1}$ affects integrin-linked kinase and focal adhesion kinase (FAK) mRNA expression, mediating the proliferation and migration of human aortic SMCs [147]. The integrin receptor/integrin-related kinase/Rac-1 pathway mediates vascular smooth muscle phenotypic transformation [148]. VSMCs can coordinate type I collagen assembly through integrin $\alpha_{2} \beta_{1}$, RhoA, and fibronectin (FN) polymerization [149]. In summary, VSMCs respond to changes in the mechanical environment by mediating their proliferation, migration, and phenotypic transition, and ECM synthesis through the mechanotransduction of integrins.

\section{Focal Adhesion Complexes}

Focal adhesion (FAs) complexes are integrin-containing protein complexes that are regulated by a network of protein-protein interactions [150]. They are formed in a spatiotemporal manner following activation of integrin transmembrane receptors [151], which are key factors in triggering cell adhesion and many other cellular processes, including cell migration, spreading, and proliferation. After activation in response to mechanical stimuli, integrins further activate FAs to complete mechanical signaling [152].

The integrin signaling pathway has a profound effect on proliferation and phenotype in porcine coronary artery SMCs, when cells adhere to FN, the integrin signaling pathway can be activated, which synergizes with the growth factor signaling pathway, leading to FAK activation and cell proliferation [153]. FAK and proline-rich tyrosine kinase 2 (Pyk2) activation by $\alpha_{v} \beta_{3}$ integrin pro- mote proliferation of PASMCs in PAH [154]. The FAKPIK3 signaling pathway interacts with integrins $\beta 1$ and $\beta 3$ and also affects VSMC proliferation and migration [155]. The $\alpha_{\mathrm{v}} \beta_{3} /$ FAK-dependent YAP pathway is activated in human aortic SMCs after percutaneous coronary intervention, and integrin $\alpha_{v} \beta_{3}$ mediates FAK phosphorylation and actin cytoskeleton reorganization, leading to dephosphorylation of YAP in hASMCs, which is involved in promoting hASMC proliferation and migration, leading to in-stent restenosis, and knockdown or inhibition of YAP reverses this phenomenon [156]. Integrin $\alpha_{\mathrm{v}} \beta_{3}$ binds to osteoprotegerin, a secreted protein upregulated in PAH patients, which in turn leads to FAK activation [157]. Integrin $\alpha_{5} \beta_{1}$ mediates FAK phosphorylation and is involved in VSMC migration [158]. The reduced interaction between integrin $\beta 3$ and FAs, the altered cytoskeleton, and downregulation of glycogen synthase kinase $3 \beta / \mathrm{NF \kappa B}$ signaling can inhibit VSMC migration [159].

Zyxin is also an adhesion patch protein, a mechanosensor for integrin-mediated responses to mechanical forces. Atomic force microscopy (AFM) was used to apply localized pulling forces to VSMCs through an FN focal adhesion induced by an FN-coated bead on the cell surface. The application of force with the AFM induced an increase of zyxin accumulation at the site of the FN-bead FA that accompanied the VSMC contractile response, and inhibition of zyxin expression using zyxin-short hairpin RNA (shRNA) also eliminated the contractile response of VSMC to AFM tension [160]. Mechanical stretch inhibits SOCS-1 mRNA and protein expression in human VSMCs. Colocalized with FAK, stretch disrupts FAK polyubiquitination and proteasomal degradation, resulting in FAK upregulation in stretched VSMCs [161]. Integrin-linked kinase regulates VSMC proliferation and migration by acting as a molecular scaffold in FA and by regulating the stability of cell-cell contact proteins and $\beta$-catenin signaling [162]. FAs interact with integrins for mechanosignaling, promoting VSMC proliferation, migration, and phenotypic transition involved in associated pathological diseases.

\section{Cell Junction}

Cell-cell junctions, particularly adheres junctions, can withstand large forces between neighboring cells and transmit the forces to the cytoskeleton [163]. Adherens junctions consist of cadherin molecules that bind homologously to cadherin on adjacent cells and, like integrinmediated adhesions, connect intracellularly to the actin cytoskeleton via numerous scaffolding proteins [164].

Cell junctions via calnexin can play an important role in several aspects of cell behaviors, including prolifera- 
tion, differentiation, apoptosis, and polarity. Abnormal mechanical forces can trigger abnormal proliferation of SMCs, and cell junctions are involved in the proliferative response of SMCs induced by mechanical stretch. SMCs, unlike ECs, respond to stretch without coming into contact with neighboring cells. In SMCs, stretch activates RhoA, whereas in ECs, stretch activates Rac1 [165]. Cadherin-11 is a regulator of ECM synthesis and tissue mechanics [166] and regulates the expression of the key transcription factor serum response factor, which is important for the transition of mesenchymal stem cells into SMCs [167]. Furthermore, cadherin-11 is necessary for the development of contractility in smooth muscle-containing tissues, such as arteries, where cadherin-11 is involved through homophilic interactions, leading to rapid activation of the transforming growth factor- $\beta$ and Rho kinase (ROCK) pathways and phosphorylation of downstream effectors. Subsequent activation of the key transcription factors myocardia-related transcription factor A (MRTF-A; also known as MKL1) and MYOCD leads to significant upregulation of collagen and elastin genes [167]; tissues containing smooth muscle or myofibroblasts, such as aorta, appear significantly impaired in mechanical strength and have significantly reduced collagen and elastin content in cadherin-11 gene deficient mice $\left(\mathrm{CDH} 11^{-/-}\right)$compared with wild-type (WT) mice, indicating that cell junctions are regulators of ECM production, and this mechanism may regulate important biomechanical processes in novel ways.

\section{Cytoskeleton}

The structural and functional integrity of the vascular wall is due in part to the interaction between the collagenand elastin-rich ECM and VSMCs. In response to mechanical force stimuli, VSMCs interact with the ECM to mediate the perception of changes in external mechanical forces by ion channels, membrane receptors, and integrin receptors on the cell membrane, which are transmitted intracellularly to myosin contractile units and induce cellular adaptation to external stress. Cells are embedded in the support network of ECM components. The ECM not only constitutes a structural scaffold but also affects cell proliferation, migration, and differentiation [168], which has a profound impact on cell behavior.

Emilin, an ECM glycoprotein, is one of the components of elastin fibers and is mainly localized at the elastin-microprotein interface [169], which has a C-terminus gC1q domain typical of the gC1q/TNF superfamily members containing an $\mathrm{N}$-terminus unique cysteine-rich EMI domain. These glycoproteins are homotrimeric and as-

VSMC Mechanosensitive Regulators and Vascular Remodeling semble into high molecular weight multimers $[19,170]$. Emilin $1 \mathrm{gClq}$ is an adhesive substrate and provides anchorage and/or homeostatic control of cell proliferation, suggesting that it might also contribute to the cell number and the size of VSMCs in arterial walls [171]. Emilin1 is implicated in elastogenesis and in maintenance of vascular cell morphology [172]. Targeted inactivation of the Emilin1 gene in mice induces multiple phenotypes characterized by a decreased diameter of arterial vessels and systemic hypertension. Vascular smooth muscle Emilin1 is a regulator of arteriolar myogenic response and blood pressure [173]. Vascular smooth muscle Emilin1 is a regulator of arteriolar myogenic response and blood pressure [174]. In mice with selective SMC ablation of Emilin1, TGF $\beta$ expression significantly increases, which stimulates heparin binding, EGF, and subsequent transactivation of EGFR, and these signals can recruit TRPC6 and TRPM4 [175]. In resistance arteries from hypertensive patients, Emilin1 decreases and the MT is enhanced, which depends on increased TGF $\beta$-EGFR signaling [175]. The dynamic rearrangement of the actin cytoskeleton is necessary to redistribute the physical forces required for cell contraction, allowing the cells to adapt to the extracellular microenvironment. Mutations in ACTA2, which encodes smooth muscle alpha-actin, result in impaired VSMCs function, which leads to a reduced ability of cells to sense matrix-mediated mechanical stimuli [176]. Transmural pressures in the aortic rings of ACTA2 $2^{-/}$ mice are lower than in WT mice at any given level of stretch. ACTA2 $2^{-/-}$cells are unable to generate external forces to remodel the matrix due to reduced contractility and interaction with the matrix [176].

In a mouse model of pressure overload induced by transverse aortic constriction surgery, biomechanical stress after p47 (phox) KO upregulates N-calmodulin and $\beta$-catenin, but disrupts the actin filament cytoskeleton and reduces phosphorylation of FAK, leading to vasoconstriction dysfunction after surgery, suggesting an important role for the cytoskeleton in mechanotransduction [177].

Intermediate filaments are involved in stress-related cellular mechanical properties and plasticity by regulating FA and the actin network. Vimentin is one of the proteins of intermediate filaments, and vimentin knockout $\left(\mathrm{Vim}^{-/-}\right)$mice have increased the expression of laminin, $\mathrm{FN}$, perlecan, type IV collagen, and VE cadherin in the subendothelial basement membrane and von Willebrand factor deposition; smooth muscle myosin heavy chain, a-SM actin, and smoothelin expression were decreased. Electron microscopy revealed enhanced smooth muscle cell-matrix interactions [178]. In $\mathrm{Vim}^{-/-}$mice, expression 
of integrin $\alpha_{\mathrm{v}}$, talin, and vinculin increases in FAs; in addition, the expression of phosphorylated FAK and its targets Src and ERK1/2 increases. Vim ${ }^{-1-}$ (but not synemin knockout) results in increased carotid artery stiffness and contractility as well as endothelial dysfunction [178]. RhoA/ROCK signaling regulates smooth muscle phenotypic modulation and vascular remodeling via the c-Jun $\mathrm{N}$-terminal kinase (JNK) pathway and vimentin cytoskeleton [179]. Vimentin also plays an important role in mechanotransduction as a cytoskeleton.

\section{Nuclear Membrane Protein}

The nucleus is not only a repository of genetic information but also actively involved in sensing changes in mechanical load. The nucleus contains actin stress fibers to maintain nuclear morphology and changes in nucleus morphology [180-182], due to mechanical forces or substrate stiffness can also lead to changes in gene expression $[183,184]$. Mechanical forces are transmitted to the nuclear membrane via the actin cytoskeleton or microtubules, leading to changes in gene expression $[185,186]$.

The main intermediate filament that makes up the nuclear membrane is lamin A. Mutations in lamin cause a disease called laminopathies, and abnormalities in lamin A can lead to premature atherosclerosis or myotonic dystrophy, which suggests that lamin plays an important role as a load-bearing structure necessary for structural integrity and normal cell nuclear mechanics [187].

In hypertensive rats, VSMC proliferation was significantly increased and emerin and lamin $\mathrm{A} / \mathrm{C}$ expression was inhibited in somatic common carotid arteries compared to normotensive controls; in an in vitro cyclic stretch model, it was consistently concluded that VSMCs under high (15\%) cyclic stretch had significantly increased proliferation and decreased expression of emerin and lamin A/C compared to normal (5\%) cyclic stretch control group [188]. Using targeted short interfering RNAs to mimic the inhibitory effect of $15 \%$ retraction on emerin or lamin A/C expression in VSMCs, the proliferation was found to be significantly enhanced under static and 5\% retraction conditions. Overexpression of emerin or lamin A/C reversed the $15 \%$ stretch-induced VSMCs proliferation. Thus, emerin and lamin A/C play a key role as mechanosensitive factors in inhibiting VSMC overproliferation induced by hyperextension [188].

In conclusion, mechanical forces can be transmitted by interacting with the ECM, ion channels, membrane receptors, or transmembrane proteins in the cell membrane, playing a central role in mechanical transduction and triggering downstream signaling cascades, leading to force-dependent changes in gene expression. Cells interacting with the ECM in a mechanical manner can also mediate a network of integrins, cytokines, cytoskeletal proteins, and coordinated changes in the nuclear structure to achieve mechanical signaling, translating physical forces into biochemical responses.

\section{Signaling Pathways}

Rho

ROCK is an effector of Rho GTPase, which increases vascular smooth muscle contractility by phosphorylating MLC and inactivating MLC phosphatase. ROCK plays a key role in the composition, differentiation, and function of the actin cytoskeleton of VSMCs and is involved in the pathogenesis of CVD $[189,190]$. A variety of extracellular stimuli activate RhoA via GPCRs.

In VSMCs, inhibition of Rho/ROCK signaling disrupts the actin cytoskeleton, which affects iNOS expression, release of NO, and consequently vascular diastolic function [191]. The VSMC glycocalyx mediates shear stress-induced contractile responses via the ROCK-myosin lightchain phosphatase pathway [192], and in VSMCs, Rho activation regulates vasoconstriction [193]. ROCK activation and ER stress can be considered cerebral autosomal dominant arteriopathy with subcortical infarcts and leukoencephalopathy (CADASIL) vasculopathy, and CADASIL vessels show impaired vasodilation, sluggish vasoconstriction, and hypertrophic remodeling. In CADASIL, with Nox5 upregulation, and increased Notch3 and ER stress target, ROCK activity, superoxide production, and cytoskeleton-associated protein phosphorylation all increase. The use of inhibitors of Notch ( $\gamma$-secretase inhibitor), Nox5 (melatonin), ER stress (4-phenylbutyric acid), and ROCK (fasudil) ameliorates the abnormal vascular response and the Notch3-Nox5/ER stress/ROCK signaling pathway in CADASIL [194]; RhoA/ROCK alters fetuin A uptake and regulates calcification in bovine VSMCs, and the RhoA/ROCK signaling pathway can act as a negative regulator of vascular calcification [195].

The Rho/ROCK pathway is involved in differential migration of human coronary artery bypass VSMCs at different sites. VSMCs' PDGFR $\beta$ expression decreased and PDGFRa increased in the internal mammary artery (MA) group compared with the saphenous vein (SV) group. In the MA group, PDGF-BB-induced lower RhoA activity and less MA-VSMC stress fiber formation than in the SV group. Dominant negative RhoA mutants inhibited stress fiber formation induced by PDGF-BB, while active mutants resulted in maximal stress fiber formation in MA and SV groups [196]. Rho is involved in the pro- 
liferation, migration, and contractile function of VSMCs in response to differences in the mechanical microenvironment in which the blood vessel is exposed.

\section{Mitogen-Activated Protein Kinase}

Protein kinases are signal transduction enzymes that catalyze the phosphorylation of specific residues in target protein substrates, which in turn exert corresponding biological effects. MAPK is a highly conserved class of serine/threonine protein kinases in cells, whose activation depends on the dual phosphorylation of threonine and tyrosine in the conserved region between the VII and VIII subdomains of the protein kinase [197]. At the molecular level, activation of the MAPK family is mediated by a specific 3-layer kinase cascade, whereby MAP3Ks/MEKKs activate MAP2Ks/MKKs and MAP2Ks in turn activate MAPK [198]. The MAPK signaling pathway has 3 subfamilies: ERK1/2, JNK/stress-activated protein kinase (SAPK), or P38 MAPK.

In acute hypertension, both JNK and ERK are activated in the vascular wall [199]. JNK is activated in the arterial wall after balloon injury or angioplasty in animals [200]. This suggests that mechanical stress is associated with JNK activation. Calcitonin-gene-related peptides partially protect cultured SMCs from oxidative stress-induced apoptosis by activating ERK1/2 MAPK [201]. In SHRs, exercise promotes a phenotypic conversion of VSMCs via Akt and MAPK, and VSMC phenotypic markers are reversed when $\mathrm{p}$-Akt inhibitors, $\mathrm{p}$-ERK inhibitors, and p-P38 MAPK inhibitors are administered [202].

Mechanical stretch increases VSMC proliferation and apoptosis by activating the protein disulfide bond isomerase (PDI) redox system, thereby accelerating the formation of atherosclerotic lesions in grafted veins [203]. The use of PDI inhibitors inhibits the PDI-ER stress system, thereby attenuating the concomitant increase in VSMC proliferation and apoptosis in response to mechanical stretch. However, MAPK inhibitors PD98059, SP600125, and SB202190 significantly reduce the activation of the ER stress signaling cascade, and the ER stress inhibitor reduces PDI activation and ER stress signaling [203], suggesting that small beriberi inhibits mechanical stretchinduced vascular smooth muscle cell proliferation and apoptosis. In summary, the MAPK signaling pathway can be used as a mechanical signaling pathway in VSMCs in response to hypertension and mechanical stretch in vitro.

\section{YAP-TAZ}

The Hippo-YAP signaling pathway plays a critical role in mechanotransduction events. Dupont et al. [204] re- ported in 2011 that $\mathrm{YAP} /$ transcriptional coactivators with PDZ-binding motifs (TAZ) can act as a mechanistic signaling transcription factor, and ECM elasticity, cell shape, and cytoskeletal forces have closely correlated with YAP/ TAZ activity and expression levels. YAP/TAZ expression can govern cellular behavior, and based on this mechanism of action, it is possible to elucidate how physical forces shape tissue morphogenesis and homeostasis in vivo (e.g., constant remodeling when the mechanical environment of the tissue changes). YAP is considered as a core component of mechanotransduction signals sensing changes in the extracellular mechanical microenvironment, such as ECM stiffness, intercellular or cell-matrix adhesion, and different cell density and cell morphology $[205,206]$. YAP transduction is associated with the tissue properties of the organ itself, such as tissue topology, mechanical properties, and organ size, and these key tissue properties determine the cell-to-cell-ECM and cell-to-cell environmental responses, which further trigger individual cytoskeletal remodeling and changes in cellular traction, thereby altering the fate of individual cells [207-209]. YAP/TAZ integrates mechanical cues with the response to soluble signals and metabolic pathways to control multiple aspects of cell behavior, including proliferation, cell plasticity, and stemness essential for tissue regeneration [210-212]. Mechanoregulation and pathology of YAP/ TAZ can via Hippo and non-Hippo mechanisms [213].

Mechanical stimuli can cause changes in the structure and dynamics of the actin cytoskeleton [214]. YAP plays a key role in actin-cytoskeleton-mediated mechanical signaling [215]. Increasing F-actin levels promotes YAP/ TAZ nuclear localization, and loss of F-actin causes YAP/ TAZ to accumulate in the cytoplasm. The sensitivity of YAP/TAZ to the status of the F-actin cytoskeleton has been harnessed not just for mechanical regulation but also for GPCR signaling, which modulates Hippo signaling by acting through Rho GTPase to increase F-actin levels [216-218]. Pressure promotes F-actin depolymerization, RhoA downregulation, and LPAR1 (Ga12/13coupled receptor) inactivation, which leads to YAP cytoplasmic translocation and decreased clustering [206].

The YAP/TAZ signaling pathway has been reported to be involved in vascular remodeling and CVD [219], such as atherosclerosis [220-222]. In ECs, YAP/TAZ responds to shear stress [223]. In mice and human ECs, laminar flow decreases the level of nuclear YAP and YAP target gene expression (connective tissue growth factor and cysteine-rich protein 61) by promoting Hippo kinase LATS1/2-dependent YAP (serine 127) phosphorylation [221]. Disturbed flow (DF, without a clear direction), not 
laminar flow (with a clear direction), activates YAP/TAZ to promote atheroprone phenotypes (proliferation and inflammation) [220]. DF also promotes YAP activation and endothelial vascular cell adhesion molecule 1 (VCAM1)-dependent inflammatory responses by increasing YAP phosphorylation (at tyrosine 357) dependent on tyrosine protein kinase activity [224]. YAP/TAZ activation in the endothelium induces JNK-mediated anti-inflammatory gene expression to promote arteriogenesis in response to DF. YAP/TAZ inhibition suppresses JNK signaling and downregulates pro-inflammatory gene expression, thereby reducing monocyte attachment and infiltration [221]. YAP/TAZ inhibition could contribute to the anti-inflammatory effect of simvastatin, and the integrin-Ga13-RhoA-YAP pathway holds promise as a novel drug target against atherosclerosis [221].

The YAP/TAZ pathway is involved in PAH [225]. ECM remodeling and pulmonary vascular stiffness activate YAP/TAZ, which induces the microRNA (miR)130/301 family expression in pulmonary artery ECs and SMCs. In turn, the miR-130/301 series inhibits miR$130 / 301$ by activating YAP and TAZ through a feedback mechanical transport cycle, which improves ECM remodeling and PAH [226]. YAP/TAZ contributes to pulmonary fibrosis and alveolar regeneration via mechanotransduction, $G$ protein-coupled receptor signaling, and a conventional Hippo/YAP signaling pathway, and selectively inhibiting YAP/TAZ in lung fibroblasts may inhibit fibroblasts' proliferation and ECM deposition [227]. During stiffness and flow sensing, YAP/TAZ tightly controls cell-ECM interactions [212]. The FA protein DLC1 is a direct transcriptional target of YAP/TAZ and is crucial for YAP-driven collective cell migration and sprouting angiogenesis by ECs $[228,229]$. YAP/TAZ is also involved in the mechanical transformation of coronary vein graft disease [230]. YAP plays an important role in 3D organogenesis, which can regulate actomyosin activity, thus participating in the regulation of $3 \mathrm{D}$ tissue morphology and alignment [231]. In hydrogels and artificial substrates, YAP/TAZ plays a critical role in stem cell proliferation and differentiation via mechanical signals [232].

This review focuses on how VSMCs undergo mechanical transduction. In human umbilical arterial SMCs (HUASMCs), cycle stretch $(0.5 \mathrm{~Hz}$, elongation $13 \%, 24 \mathrm{~h})$ leads to PI3K and phosphatidylinositol-dependent kinase 1 activation. Phosphatidylinositol-dependent kinase 1 activation triggers the dissociation of Hippo core kinases from the scaffolding protein SAV1/WW45, leading to Lats inactivation, dephosphorylation, and YAP nuclear translocation [233]. In addition, YAP/TAZ knockdown significantly attenuates mechanic-induced proliferation and pro-inflammatory phenotypes in HUASMCs [233]. In the VSMCs of aortic walls of patients with ascending aortic aneurysms, the expression of YAP was significantly reduced, which is associated with ECM disorders of the media in ascending aortic aneurysms [234]. VSMCs secrete significantly more Thbs1, which binds via integrin $\alpha_{v} \beta_{1}$ and establishes mature FAs, facilitating YAP nuclear shuttle in a small GTPase RAP2- and Hippo-dependent manner, thereby leading to Thbs 1/integrin/YAP-mediated matrix mechanotransduction in vascular remodeling [235]. The thromboxane $A_{2}$ receptor (TP) signaling activates YAP/TAZ and promotes DNA synthesis and cell migration in VSMCs to facilitate VSMC proliferation and migration, and participates in the restenosis process after vascular injury. Knockdown of TP or knockdown of the downstream $\mathrm{G}$ protein Ga12/13 blocks YAP activation; in addition, the Rho inhibitor of the actin cytoskeleton disruption also prevents YAP/TAZ activation [236]. cAMP-induced actin cytoskeleton remodeling suppresses YAP/TAZ-TEAD-dependent mitogenic gene expression in VSMCs. Exerting an anti-promitogenic effect inhibits excessive proliferation of VSMCs and prevents postvascular restenosis and vein graft failure [237]. The YAP signaling pathway is also involved in the phenotypic transformation of VSMCs, in vitro and in vivo arterial injury models, YAP expresses the increase in ions, which promotes SMCs migration and proliferation, while attenuating smooth muscle contractile gene expression and neointima formation [238].

\section{SMCs Are Involved in ECM Secretion and Remodeling in Response to Mechanical Stimulation}

The ECM is the structural entity that surrounds and supports tissues and cells. The ECM consists of many tissue-specific proteins, such as collagen, proteoglycans, elastin, glycoproteins, MMPs, and growth factors [239]. Mechanical stimuli are delivered to cells via the ECM, which provides an adhesive surface for cells and tissue structures. In addition, cells can interact dynamically with the ECM and synthesize, degrade, and rearrange it $[240,241]$. VSMCs are located in the middle layer of the vascular system and are primarily subjected to cyclic tensile force caused by blood pressure and are responsible for vascular contraction and remodeling. When the lumen is under high pressure or when cyclic stretch is exerted in vitro, VSMCs sense changes in the mechanical stress to which they are subjected and regulate the expression and 
synthesis of ECM molecules to adapt to changes in the external mechanical environment through ion channels, transmembrane proteins, integrins, signaling cascades, and mechanosensitive pathways described before.

In hypertensive patients, the mechanical tension of arteries increases by $\sim 15 \%$, with a corresponding increase in collagen [242]. The expression profile of ECM genes was examined in VSMCs from chronic overloaded PAH by real-time PCR, and stress-induced ECM protein expression was significantly elevated [243].

In an in vitro stretch model, collagen synthesis in SMCs increased with increasing circumferential strain. When cyclic stretch $(20 \%, 1 \mathrm{~Hz})$ was performed for $20 \mathrm{~h}$, there were 87 significant differences in the expression of secreted proteins in rat VSMCs (2-fold differences). Gene ontology analysis revealed that these differential genes are involved in ECM secretion and reorganization, such as a significant increase in Thbs1 secretion by VSMCs, which is involved in vascular remodeling via integrin/YAP signaling [235]. After 5 days of cyclic stretch $(25 \%, 0.05 \mathrm{~Hz})$, total protein and collagen synthesis significantly increased [244]. Long-term (6 days) circumferential strain upregulated both collagen type III and elastin gene expression [245]. In cyclically strained human aortic SMCs, thrombomodulin and MMP-1 expression reduced and ECM synthesis increased [246]. Cyclic stretch stimulation induced a switch from a contractile phenotype to a synthetic phenotype in VSMCs, and mechanical strain induced increased AT1 receptor protein expression, increased collagen $\alpha 1$ and FN synthesis, and increased ECM synthesis compared to static cells [247].

In in vitro $3 \mathrm{D}$ tissue-engineered matrix vascular cultures, collagen content increased under pulsatile conditions $(5 \%, 2.75 \mathrm{~Hz})$ compared to static cells when SMCs and ECs were grown together on polyglycolic acid scaffolds [248]; SMCs on collagen scaffolds under cyclic stretch $(2.5 \%-$ $10 \%, 0.5 \mathrm{~Hz}$ ) showed no change in collagen synthesis, but elastin protein synthesis significantly increased [249]; HUASMCs were added to a $3 \mathrm{D}$ collagen matrix and cultured for 7 days under cyclic stretch $(5 \%, 0.1 \mathrm{~Hz}-\mathrm{Hz})$, which showed increased collagen, elastin, and MMP-2 expression and increased matrix remodeling over time at increasing cyclic mechanical strain frequencies [250]. Similar conclusions were obtained in previous studies by our group. HUASMCs were grown on a polyglycolic acid scaffold with a pneumatic left heart circulation assist pump as the driving device to provide a pulsatile tensile stress environment (120 $\mathrm{mm} \mathrm{Hg}, 1 \mathrm{~Hz}$ ) and cultured continuously for 4 weeks. During this period, the tissue-engineered blood vessels (TEBVs) were measured by optical coherence tomography to de-

VSMC Mechanosensitive Regulators and Vascular Remodeling tect changes in its thickness to predict vascular remodeling. Results showed a significant increase in TEBV thickness and a denser tissue structure in the pulsed group compared to the nonpulsed group, as well as a significant increase in collagen expression $[251,252]$.

Cyclic stretching of aortic SMCs in 2D culture resulted in a 2 -fold increase in the expression of hyaluronic acid and chondroitin 6-sulfate in SMCs compared to the unstretched group [253]. Mechanical stretch also resulted in the shedding of syndecan- 4 from the cell surface, which facilitated cell motility by reducing local adhesions [254]. MMP synthesis in SMCs was also regulated by cyclic stretch, and in in vitro mechanical stretch model, mechanical stretch promoted the expression of MMP7 and MMP11 in rat VSMCs [255]. In mechanically stretched venous and arterial SMCs, the MMP-2 and MMP-9 expression increased significantly [256-258].

These studies suggest that mechanical stress plays an important role in tissue remodeling and tissue engineering applications, and that in vitro mechanical stimulation by cyclic stretch almost consistently increases ECM synthesis in SMCs and performs remodeling. This suggests that cellular remodeling can be directed to improve arterial regeneration and remodeling through the use of cyclic mechanical stimulation.

\section{Mechanosensitive Pathways in SMCs Are Involved in Vascular Remodeling}

Blood pressure plays an important role in regulating vascular structure and function. ECs in the vasculature are dynamic regulators of blood flow, inflammation, and coagulation. VSMCs are the main cells of the arterial cell mass and are important in maintaining the dynamic changes in the arterial structure and optimizing arterial mechanics [259].

Under normal physiological conditions, mechanical stimulation induces ECs to release and balance the effects of vasodilators and vasoconstrictors, thereby maintaining normal vascular tone. However, under pathophysiological conditions, the persistent abnormal increase in mechanical stress induced by hypertension leads to alterations in vascular structure and function. VSMCs play a key role in vascular remodeling by responding to the increased pressure on the blood vessel wall and affecting important biological functions such as cell proliferation, cell migration, and ECM synthesis [9].

In animal models of hypertension, with increased proliferation of VSMCs, for example, induced by Ang II in- 
jection in mice, Piezo1 ion channel opening increases the cytoplasmic $\mathrm{Ca}^{2+}$ concentration in the VSMCs, and specific knockdown of the Piezol gene leads to reduced activity of triglycerides [43], which play an important role in arterial SMC proliferation and PAH [260]. Piezo1 gene deletion leads to a significant reduction in the arterial diameter, wall thickness, and cross-sectional area [43]. In an SHR disease model, multiple isoforms of TRP channels are activated and activated TRP mediates elevated intracellular $\mathrm{Ca}^{2+}$ and $\mathrm{Na}^{+}$[50]. In PAH, TRPM7 is downregulated to activate the MEK/ERK pathway and intracellular $\mathrm{Mg}^{2+}$ levels are reduced [59]; in addition, mechanical stretch potentiating the Ang II type 1/EGFR/ERK-dependent signaling pathway directly regulates VSMC proliferation induced in SHR [133]. Activation of tyrosine kinase phosphorylation in SMCs in hypertension [125] and activation of the MAPK signaling pathway both promote VSMC proliferation and migration [203]. In addition, the cytoskeletal proteins emerin and lamin A/C, which are involved in regulating cellular function in response to cyclic stretch, can also induce VSMC proliferation [188].

In hypertension, there is increased production of reactive oxygen species (ROS), which can crosstalk with intracellular free $\mathrm{Ca}^{2+}$ signaling, with the involvement of TRPM channels $[60,261]$; reactive oxygen species can contribute to the conversion of VSMCs from a contractile to a synthetic phenotype $[262,263]$; activation of the MAPK signaling pathway can also mediate SMC phenotypic conversion [202, 264]. Effectors of the Hippo pathway, YAP-TAZ, are involved in stretch-induced phenotypic conversion of human umbilical vein VSMCs to a synthetic state and also regulate the proliferation and survival of pulmonary artery VSMCs and pulmonary arterial remodeling [233].

These studies suggest that mechanosensitive regulators of VSMCs responses to mechanistic stimuli can be activated in hypertension-related diseases, and that various signaling pathways can interact and cross talk to some extent, affecting cell proliferation, cell migration, and ECM synthesis, further participating in the development of vascular remodeling.

\section{Mechanosensitive Pathways in VSMCs Are Involved in Tissue-Engineered Blood Vessels}

CVD is a serious disease threatening human health. Ischemic diseases, such as atherosclerotic, remain one of the leading causes of mortality and morbidity worldwide.
These diseases have led to a continuous need for vascular grafts to solve problems such as reconstruction or vascular occlusion and aneurysms $[265,266]$. With the complications of vascular transplantation surgery, the frequent shortage of autologous vascular grafts, and the immune rejection of large-animal-derived vessels [267-269], artificial vascular grafts were first introduced in the 1950s to replace occluded arterial vessels [270]. However, despite advances in all aspects of pharmacology, materials science, and equipment manufacturing, the implantation of these synthetic vascular grafts did not significantly reduce overall mortality and morbidity, and synthetic small-diameter vascular grafts have disadvantages such as low vascular compliance and patency [271], the need for repeated interventions in the pediatric population, and susceptibility to infection.

A TEBV is prepared, constructed, or regenerated by mimicking normal blood vessel wall cells and ECM components and their combinatorial arrangement. The evaluation criteria include high vessel compliance, strong mechanical properties, low thrombosis and regenerative remodeling, and, ultimately, successful fusion after implantation [272, 273]. To obtain a good-quality TEBV, it is important to consider the structure of the blood vessel as well as the microenvironment in which it resides. The mechanical microenvironment in the body has a significant impact on the mechanical properties of blood vessels. The tension and shear stress of blood vessels caused by vascular pulsation and blood flow in a physiological state stimulate the proliferation and migration of ECs and VSMCs and the secretion of corresponding growth factors, which regulate the barrier function of blood vessels and the formation of collagen and elastic fibers. Therefore, without considering biomechanical stimuli, the constructed blood vessels will lack sufficient mechanical strength to obtain a tissue structure and mechanical properties close to those of natural blood vessels. At present, the 2 main challenges facing TEBV development are that it lacks sufficient elastic mid-membrane support under static conditions in vitro and it is not mechanically strong with similar mechanical properties as natural blood vessels. After implantation, autologous cells have difficulty growing, particularly ECs, resulting in low long-term patency rates. Therefore, it is of great significance to find a method of constructing a TEBV that mimics the cardiac pulsatile vasomechanical microenvironment in vivo.

Laura E. Niklason's team has developed a TEBV based on an in vitro bioreactor that induces ECM secretion from target cells inoculated on a biodegradable scaffold by applying appropriate mechanical stimuli, after ECM 
remodeling, resulting in a TEBV with good biochemical and mechanical properties [274]. The TEBV based on this method is the first artificial blood vessel to enter phase III clinical trials for use in the hemodialysis pipeline for patients with end-stage renal disease. After decellularization and implantation, recruitment of host myofibroblasts, ECs, and progenitor cells transforms the previously acellular TEBV into a functional, multilayered living tissue that maintains blood transport and exhibits self-repair after cannulation injury, effectively making it like the patient's own vessels [275]. To make a biological engineered artery to function successfully, it needs to meet the requirements of stringent design criteria, including ECM of sufficient quality to provide suitable tensile, suture retention, and rupture strength properties [273]. It is necessary to ensure that the artificial artery can assume the natural physiological function and that, when implanted in the body, it functions immediately without any maturation period to be fully competent in terms of mechanical strength or inflammatory properties [273]. The mechanical stimulus is a crucial factor, and it is therefore essential to obtain a TEBV with good mechanical properties (appropriate tensile strength, suture retention, and fracture strength properties) by mimicking as closely as possible the specific mechanical microenvironment in which the in vivo blood vessel is located during TEBV culture, allowing it to secrete and remodel the ECM.

TEBV in vitro by using pulsatile perfusion bioreactors and elastic PLCL scaffolds enhances tissue development and the retention of the differentiated cell phenotype, and the mechanical stimulation $(1 \mathrm{~Hz}, 5 \%$ radial distention of the initial radius) induces cellular alignment and contractile phenotype of SMCs in bioengineered tissues [276]. The incremental addition of pulsatile radial stress at 110 120 beats per minute (bpm) significantly heightens the mechanical properties of the human-induced pluripotent stem cell-SMCs-TEBV [277]. In a bioreactor system, cyclic mechanical strain $(1 \mathrm{~Hz}, 10 \%$ radial distention) was applied to engineered vascular constructs made of isolated SMCs in a 3-dimensional (3D) collagen type $1 \mathrm{ma}-$ trix, which causes a characteristic increase in gel compaction and cell proliferation, and expression of the contractile protein smooth muscle alpha-actin [278].

In previous studies, we constructed bioreactor-based 3D culture systems with adjustable mechanical parameters, successfully cultured a TEBV with well-arranged collagen fibers and good mechanical properties [251, 252], and established a quantitative system for quantifying the mechanical stimuli applied to the TEBV [279]. The composition, metrics, and mechanical properties of

VSMC Mechanosensitive Regulators and Vascular Remodeling the cultured TEBV differed significantly between the different intensities of circumferential stress stimulated over time. Therefore, it is important to clarify how circumferential stress stimulation mediates SMC behavior and thus affects TEBV construction and to investigate its molecular mechanisms in order to lay a foundation for targeted improvement of the conditions for TEBV construction. Different types of mechanical stretch can elicit different molecular and cellular responses [280]. Circumferential stress regulates VSMC proliferation, apoptosis, and migration, as well as collagen synthesis, degradation, and reorganization [281], and the unique mechanical properties of blood vessels are closely related to the distribution and arrangement of collagen fibers. Whether the mechanosensitive molecules and signaling pathways in SMCs mentioned before are involved in the construction of a TEBV and how much they contribute to the formation of the mechanical properties of a TEBV remain to be further studied.

\section{Perspectives}

Circumferential stress induced by pulsatile blood pressure activates intracellular signaling networks through a variety of mechanosensory mechanisms that regulate VSMCs function, which in turn regulates transcription factor/gene expression and cellular function. With increasing research on the regulation of mechanical stress and its effects on cell structure and function in recent years, the mechanisms by which VSMCs and ECs respond to adaptive stress and mechanical transduction are gradually being understood. However, there are still many unknown details in this field, such as the effects of mechanical form of loading, the pressure waveform of mechanical loading on cells, the effects of the size and frequency of mechanical stimulation on the biochemical function of VSMCs and ECs, and the effects of mechanical stimulation on the formation, repair, and reconstruction of vascular tissue and TEBVs in vitro, as well as the mechanisms of mechanical signal transduction and regulation of gene expression in VSMCs and ECs during this process.

Therefore, further exploration of mechanosensitive signaling in vascular cells under stress and the mechanobiology of mechanics affecting vascular cellular activity will help to understand the role of mechanics in the pathogenesis of certain diseases (e.g., vascular diseases) and in the repair process after damage, allowing for targeted countermeasure strategies. It is also of great signif- 
icance in the field of tissue engineering and regenerative medicine. Currently, there is a great clinical need for engineered arterial replacement for the treatment of atherosclerotic diseases, infections, and traumatic injury diseases. However, the equally enormous simultaneous challenges of immune acceptance, requisite tissue mechanics, low thrombogenicity, and immediate availability have made the broad clinical application of engineered arteries quite difficult to achieve [273]. Understanding the effects of mechanical factors on vascular cells and the underlying mechanisms is of great importance to optimize engineered blood vessel construction.

In this review, we described the molecules involved in the VSMCs response to circumferential stress/cyclic stretch, including mechanosensitive ion channels, membrane receptors or transmembrane proteins, integrins, cytoskeletal proteins, and nuclear structures, which translate mechanical stimuli into biochemical events and ultimately lead to some basic mechanisms of biological responses. The understanding of more such proteins/molecules and mechanosensitive signaling pathways will help us identify the intracellular mechanisms of key signaling pathways and elucidate more clearly CVD pathogenesis, as well as helping to address a major challenge currently faced by TEBVs-the lack of sufficient mechanical properties. Selecting appropriate mechanical stimulation conditions, as well as genome-editing techniques to intervene with defined mechanically sensitive regulatory molecules in the future, to direct the biological behavior of VSMCs and to secrete and reconstitute the ECM, will guide the development of more effective clinical therapies.

\section{Acknowledgments}

Dr. Yueheng Wu gave some suggestions about the manuscript.

\section{Statement of Ethics}

The authors have no ethical conflicts to disclose.

\section{Conflict of Interest Statement}

The authors have no conflicts of interest to declare.

\section{Funding Sources}

The work was supported by grants from the Ji Hua Laboratory in Foshan city (X210111TD210) and the Summit Program of Guangdong General Hospital (DFJH201904).

\section{Author Contributions}

S.L. conceived, wrote, and revised the manuscript. Z.L. conceived, revised the manuscript, and approved the final version of the manuscript.

\section{Data Availability Statement}

Data sharing is not applicable to this review article as no datasets were generated or analyzed during the current study.

\section{References}

1 Ingber DE. Cellular mechanotransduction: putting all the pieces together again. FASEB J. 2006 May;20(7):811-27.

2 Janmey PA, McCulloch CA. Cell mechanics: integrating cell responses to mechanical stimuli. Annu Rev Biomed Eng. 2007;9:1-34.

3 Fung FC, Biomechanics C. Motion, flow, stress, and growth. J Appl Mech. 1993;60(2): 139.

4 Discher DE, Janmey P, Wang YL. Tissue cells feel and respond to the stiffness of their substrate. Science. 2005 Nov 18;310(5751):113943.

5 Souilhol C, Serbanovic-Canic J, Fragiadaki M, Chico TJ, Ridger V, Roddie H, et al. Endothelial responses to shear stress in atherosclerosis: a novel role for developmental genes. Nat Rev Cardiol. 2020 Jan;17(1):5263.

6 Risau W. Mechanisms of angiogenesis. Nature. 1997 Apr 17;386(6626):671-4.
7 Hogan BM, Schulte-Merker S. How to plumb a pisces: understanding vascular development and disease using zebrafish embryos. Dev Cell. 2017 Sep 25;42(6):567-83.

8 Owens GK, Kumar MS, Wamhoff BR. Molecular regulation of vascular smooth muscle cell differentiation in development and disease. Physiol Rev. 2004 Jul;84(3):767-801.

9 Chen J, Zhou Y, Liu S, Li C. Biomechanical signal communication in vascular smooth muscle cells. J Cell Commun Signal. 2020 Dec; 14(4):357-76

10 FitzGibbon GM, Leach AJ, Kafka HP, Keon WJ. Coronary bypass graft fate: long-term angiographic study. J Am Coll Cardiol. 1991 Apr;17(5):1075-80.

11 Goldstone $A B$, Chiu P, Baiocchi M, Wang H, Lingala B, Boyd JH, et al. Second arterial versus venous conduits for multivessel coronary artery bypass surgery in California. Circulation. 2018 Apr 17;137(16):1698-707.
12 Kaess BM, Rong J, Larson MG, Hamburg NM, Vita JA, Levy D, et al. Aortic stiffness, blood pressure progression, and incident hypertension. JAMA. 2012 Sep 5;308(9):87581.

13 Korneva A, Humphrey JD. Maladaptive aortic remodeling in hypertension associates with dysfunctional smooth muscle contractility. Am J Physiol Heart Circ Physiol. 2019 Feb 1;316(2):H265-H78.

14 Fang Y, Wu D, Birukov KG. Mechanosensing and mechanoregulation of endothelial cell functions. Compr Physiol. 2019 Mar 15;9(2): 873-904.

15 Secomb TW. Hemodynamics. Compr Physiol. 2016 Mar 15;6(2):975-1003.

16 Lacolley P, Regnault V, Segers P, Laurent S. Vascular smooth muscle cells and arterial stiffening: relevance in development, aging, and disease. Physiol Rev. 2017 Oct 1;97(4): 1555-617. 
17 Owens GK. Role of mechanical strain in regulation of differentiation of vascular smooth muscle cells. Circ Res. 1996 Nov;79(5):10545.

18 Stegemann JP, Hong H, Nerem RM. Mechanical, biochemical, and extracellular matrix effects on vascular smooth muscle cell phenotype. J Appl Physiol. 1985 Jun;98(6):2321-7.

19 Gomez D, Owens GK. Smooth muscle cell phenotypic switching in atherosclerosis. Cardiovasc Res. 2012 Jul 15;95(2):156-64.

20 Yang K, Ren J, Li X, Wang Z, Xue L, Cui S, et al. Prevention of aortic dissection and aneurysm via an ALDH2-mediated switch in vascular smooth muscle cell phenotype. Eur Heart J. 2020 Jul 7;41(26):2442-53.

21 Wayman BH, Taylor WR, Rachev A, Vito RP. Arteries respond to independent control of circumferential and shear stress in organ culture. Ann Biomed Eng. 2008 May;36(5):67384.

22 Price RJ, Skalak TC. Circumferential wall stress as a mechanism for arteriolar rarefaction and proliferation in a network model. Microvasc Res. 1994 Mar;47(2):188-202.

23 Luo W, Garcia-Gonzalez I, FernándezChacón M, Casquero-Garcia V, Sanchez-Muñoz MS, Mühleder S, et al. Arterialization requires the timely suppression of cell growth. Nature. 2021 Jan;589(7842):437-41.

24 Anwar MA, Shalhoub J, Lim CS, Gohel MS, Davies AH. The effect of pressure-induced mechanical stretch on vascular wall differential gene expression. J Vasc Res. 2012;49(6): 463-78.

25 Na S, Collin O, Chowdhury F, Tay B, Ouyang $\mathrm{M}$, Wang $\mathrm{Y}$, et al. Rapid signal transduction in living cells is a unique feature of mechanotransduction. Proc Natl Acad Sci USA. 2008 May 6;105(18):6626-31.

26 Wang N, Tytell JD, Ingber DE. Mechanotransduction at a distance: mechanically coupling the extracellular matrix with the nucleus. Nat Rev Mol Cell Biol. 2009 Jan;10(1):7582.

27 Beech DJ. Ion channel switching and activation in smooth-muscle cells of occlusive vascular diseases. Biochem Soc Trans. 2007 Nov; 35(Pt 5):890-4.

28 Gottlieb PA, Bae C, Sachs F. Gating the mechanical channel Piezo1: a comparison between whole-cell and patch recording. Channels. 2012 Jul;6(4):282-9.

$29 \mathrm{Wu}$ J, Lewis AH, Grandl J. Touch, tension, and transduction - the function and regulation of piezo ion channels. Trends Biochem Sci. 2017 Jan;42(1):57-71.

30 Beech DJ, Kalli AC. Force sensing by piezo channels in cardiovascular health and disease. Arterioscler Thromb Vasc Biol. 2019 Nov; 39(11):2228-39.

31 Douguet D, Patel A, Xu A, Vanhoutte PM, Honoré E. Piezo ion channels in cardiovascular mechanobiology. Trends Pharmacol Sci. 2019 Dec;40(12):956-70

32 Wang S, Chennupati R, Kaur H, Iring A, Wettschureck N, Offermanns S. Endothelial cat- ion channel PIEZO1 controls blood pressure by mediating flow-induced ATP release. J Clin Invest. 2016 Dec 1;126(12):4527-36.

33 Iring A, Jin YJ, Albarrán-Juárez J, Siragusa M, Wang S, Dancs PT, et al. Shear stress-induced endothelial adrenomedullin signaling regulates vascular tone and blood pressure. J Clin Invest. 2019 Jun 17;129(7):2775-91.

34 Wang S, Iring A, Strilic B, Albarran Juarez J, Kaur H, Troidl K, et al. P2Y(2) and Gq/G(1) (1) control blood pressure by mediating endothelial mechanotransduction. J Clin Invest. 2015 Aug 3;125(8):3077-86.

35 Caolo V, Debant M, Endesh N, Futers TS, Lichtenstein L, Bartoli F, et al. Shear stress activates ADAM10 sheddase to regulate Notch1 via the Piezo1 force sensor in endothelial cells. Elife. 2020 Jun 2;9:9.

36 Morrow D, Sweeney C, Birney YA, Cummins PM, Walls D, Redmond EM, et al. Cyclic strain inhibits Notch receptor signaling in vascular smooth muscle cells in vitro. Circ Res. 2005 Mar 18;96(5):567-75.

37 Rode B, Shi J, Endesh N, Drinkhill MJ, Webster PJ, Lotteau SJ, et al. Piezol channels sense whole body physical activity to reset cardiovascular homeostasis and enhance performance. Nat Commun. 2017 Aug 24;8(1):350.

38 Beech DJ. Endothelial Piezol channels as sensors of exercise. J Physiol. 2018 Mar 15;596(6): 979-84.

39 Duchemin AL, Vignes H, Vermot J. Mechanically activated piezo channels modulate outflow tract valve development through the Yap1 and Klf2-Notch signaling axis. Elife. 2019 Sep 16;8:8.

40 Li J, Hou B, Tumova S, Muraki K, Bruns A, Ludlow MJ, et al. Piezo1 integration of vascular architecture with physiological force. $\mathrm{Na}-$ ture. 2014 Nov 13;515(7526):279-82.

41 Ranade SS, Qiu Z, Woo SH, Hur SS, Murthy SE, Cahalan SM, et al. Piezo1, a mechanically activated ion channel, is required for vascular development in mice. Proc Natl Acad Sci USA. 2014 Jul 15;111(28):10347-52.

42 Zeng WZ, Marshall KL, Min S, Daou I, Chapleau MW, Abboud FM, et al. PIEZOs mediate neuronal sensing of blood pressure and the baroreceptor reflex. Science. 2018 Oct 26; 362(6413):464-7.

43 Retailleau K, Duprat F, Arhatte M, Ranade SS, Peyronnet R, Martins JR, et al. Piezol in smooth muscle cells is involved in hypertension-dependent arterial remodeling. Cell Rep. 2015 Nov 10;13(6):1161-71.

44 Gaub BM, Müller DJ. Mechanical stimulation of Piezo1 receptors depends on extracellular matrix proteins and directionality of force. Nano Lett. 2017 Mar 8;17(3):2064-72.

45 Earley S, Brayden JE. Transient receptor potential channels in the vasculature. Physiol Rev. 2015 Apr;95(2):645-90

46 Brayden JE, Earley S, Nelson MT, Reading S. Transient receptor potential (TRP) channels, vascular tone and autoregulation of cerebral blood flow. Clin Exp Pharmacol Physiol. 2008 Sep;35(9):1116-20.
47 Sharif-Naeini R, Folgering JH, Bichet D, Duprat F, Lauritzen I, Arhatte M, et al. Polycystin-1 and -2 dosage regulates pressure sensing. Cell. 2009 Oct 30;139(3):587-96.

48 Bulley S, Fernández-Peña C, Hasan R, Leo MD, Muralidharan P, Mackay CE, et al. Arterial smooth muscle cell PKD2 (TRPP1) channels regulate systemic blood pressure. Elife. 2018 Dec 4;7.

49 Hasan R, Leo MD, Muralidharan P, Mata-Daboin A, Yin W, Bulley S, et al. SUMO1 modification of $\mathrm{PKD} 2$ channels regulates arterial contractility. Proc Natl Acad Sci USA. 2019 Dec 10

50 Martin-Bornez M, Galeano-Otero I, Del Toro $\mathrm{R}$, Smani T. TRPC and TRPV channels' role in vascular remodeling and disease. Int $\mathrm{J} \mathrm{Mol}$ Sci. 2020 Aug 25;21(17):6125.

51 Dietrich A, Mederos Y. Schnitzler M, Gollasch M, Gross V, Storch U, Dubrovska G, et al. Increased vascular smooth muscle contractility in TRPC6-/- mice. Mol Cell Biol. 2005 Aug; 25(16):6980-9.

52 Nemeth Z, Hildebrandt E, Ryan MJ, Granger JP, Drummond HA. Pressure-induced constriction of the middle cerebral artery is abolished in TrpC6 knockout mice. Am J Physiol Heart Circ Physiol. 2020 Jul 1;319(1):H42-50.

53 Numaga-Tomita T, Shimauchi T, Oda S, Tanaka T, Nishiyama K, Nishimura A, et al. TRPC6 regulates phenotypic switching of vascular smooth muscle cells through plasma membrane potential-dependent coupling with PTEN. FASEB J. 2019 Sep;33(9):9785-96.

54 Yamamura H, Suzuki Y, Yamamura A. Pathophysiological roles of TRPC6 channels in pulmonary arterial hypertension. Nihon Yakurigaku Zasshi. 2020;155(4):230-5.

55 Muraki K, Iwata Y, Katanosaka Y, Ito T, Ohya $\mathrm{S}$, Shigekawa M, et al. TRPV2 is a component of osmotically sensitive cation channels in murine aortic myocytes. Circ Res. 2003 Oct 31;93(9):829-38.

56 Soni H, Peixoto-Neves D, Matthews AT, Adebiyi A. TRPV4 channels contribute to renal myogenic autoregulation in neonatal pigs. Am J Physiol Renal Physiol. 2017 Nov 1; 313(5):F1136-F48.

57 Gao F, Wang DH. Hypotension induced by activation of the transient receptor potential vanilloid 4 channels: role of $\mathrm{Ca} 2+$-activated $\mathrm{K}+$ channels and sensory nerves. J Hypertens. 2010 Jan;28(1):102-10.

58 Goldenberg NM, Wang L, Ranke H, Liedtke W, Tabuchi A, Kuebler WM. TRPV4 is required for hypoxic pulmonary vasoconstriction. Anesthesiology. 2015 Jun;122(6):133848.

59 Wang D, Zhu ZL, Lin DC, Zheng SY, Chuang KH, Gui LX, et al. Magnesium supplementation attenuates pulmonary hypertension via regulation of magnesium transporters. Hypertension. $2021 \mathrm{Feb} ; 77(2): 617-31$.

60 Thakore P, Pritchard HAT, Griffin CS, Yamasaki E, Drumm BT, Lane C, et al. TRPML1 channels initiate $\mathrm{Ca}(2+)$ sparks in vascular smooth muscle cells. Sci Signal. 2020 Jun 23; 13(637). 
61 Mathie A, Veale EL. Therapeutic potential of neuronal 2-pore domain potassium-channel modulators. Curr Opin Investig Drugs. 2007 Jul;8(7):555-62.

62 Gurney A, Manoury B. Two-pore potassium channels in the cardiovascular system. Eur Biophys J. 2009 Mar;38(3):305-18.

63 Morita H, Komuro I. A novel channelopathy in pulmonary arterial hypertension. $\mathrm{N}$ Engl J Med. 2013 Nov 28;369(22):2161-2.

64 Brohawn SG. How ion channels sense mechanical force: insights from mechanosensitive K2P channels TRAAK, TREK1, and TREK2. Ann N Y Acad Sci. 2015 Sep;1352: 20-32.

65 Salomonsson M, Brasen JC, Sorensen CM. Role of renal vascular potassium channels in physiology and pathophysiology. Acta Physiol. 2017 Sep;221(1):14-31.

66 Sanders KM, Koh SD. Two-pore-domain potassium channels in smooth muscles: new components of myogenic regulation. J Physiol. 2006 Jan 1;570(Pt 1):37-43.

67 Patel AJ, Honoré E, Maingret F, Lesage F, Fink M, Duprat F, et al. A mammalian two pore domain mechano-gated S-like $\mathrm{K}+$ channel. Embo J. 1998 Aug 3;17(15):4283-90.

68 Chemin J, Patel AJ, Duprat F, Lauritzen I, Lazdunski M, Honoré E. A phospholipid sensor controls mechanogating of the $\mathrm{K}+$ channel TREK-1. Embo J. 2005 Jan 12;24(1):44-53.

69 Kiyoshi H, Yamazaki D, Ohya S, Kitsukawa M, Muraki K, Saito SY, et al. Molecular and electrophysiological characteristics of $\mathrm{K}+$ conductance sensitive to acidic $\mathrm{pH}$ in aortic smooth muscle cells of WKY and SHR. Am J Physiol Heart Circ Physiol. 2006 Dec;291(6):H2723-34.

70 Soubrier F, Chung WK, Machado R, Grünig E, Aldred M, Geraci M, et al. Genetics and genomics of pulmonary arterial hypertension. Turk Kardiyol Dern Ars. 2014 Oct;42(Suppl 1):17-28.

71 Liu B, Zhu L, Yuan P, Marsboom G, Hong Z, Liu J, et al. Comprehensive identification of signaling pathways for idiopathic pulmonary arterial hypertension. Am J Physiol Cell Physiol. 2020 May 1;318(5):C913-C30.

72 Antigny F, Hautefort A, Meloche J, BelacelOuari M, Manoury B, Rucker-Martin C, et al. Potassium channel subfamily $\mathrm{K}$ member 3 (KCNK3) contributes to the development of pulmonary arterial hypertension. Circulation. 2016 Apr 5;133(14):1371-85.

73 Lambert M, Capuano V, Boet A, Tesson L, Bertero T, Nakhleh MK, et al. Characterization of Kcnk3-mutated rat, a novel model of pulmonary hypertension. Circ Res. 2019 Sep 13;125(7):678-95.

74 Burg ED, Remillard CV, Yuan JX. Potassium channels in the regulation of pulmonary artery smooth muscle cell proliferation and apoptosis: pharmacotherapeutic implications. Br J Pharmacol. 2008 Mar;153(Suppl 1):S99-S111.

75 Wipff J, Dieudé P, Guedj M, Ruiz B, Riemekasten G, Cracowski JL, et al. Association of a KCNA5 gene polymorphism with systemic sclerosis-associated pulmonary arterial hy- pertension in the European Caucasian population. Arthritis Rheum. 2010 Oct;62(10): 3093-100

76 Mutchler SM, Kirabo A, Kleyman TR. Epithelial sodium channel and salt-sensitive hypertension. Hypertension. 2021 Jan 25.

77 Schild L. The ENaC channel as the primary determinant of two human diseases: liddle syndrome and pseudohypoaldosteronism. Nephrologie. 1996;17(7):395-400.

78 Nam HY, Murali MR, Ahmad RE, PingguanMurphy B, Raghavendran HRB, Kamarul T. Mechanical strain-mediated tenogenic differentiation of mesenchymal stromal cells is regulated through epithelial sodium channels. Stem Cells Int. 2020;2020:5385960.

79 Drummond HA. ENaC Proteins in vascular smooth muscle mechanotransduction. Curr Top Membr. 2007;59:127-53.

80 Drummond HA, Grifoni SC, Jernigan NL. A new trick for an old dogma: $\mathrm{ENaC}$ proteins as mechanotransducers in vascular smooth muscle. Physiology. 2008 Feb;23:23-31.

81 Drummond HA, Jernigan NL, Grifoni SC. Sensing tension: epithelial sodium channel/ acid-sensing ion channel proteins in cardiovascular homeostasis. Hypertension. 2008 May;51(5):1265-71.

82 Henrion D, Laher I, Klaasen A, Bevan JA. Myogenic tone of rabbit facial vein and posterior cerebral artery is influenced by changes in extracellular sodium. Am J Physiol. 1994 Feb; 266(2 Pt 2):H377-83.

83 Chung WS, Weissman JL, Farley J, Drummond HA. $\beta \mathrm{ENaC}$ is required for whole cell mechanically gated currents in renal vascular smooth muscle cells. Am J Physiol Renal Physiol. 2013 Jun 15;304(12):F1428-37.

84 Drummond HA, Gebremedhin D, Harder DR. Degenerin/epithelial $\mathrm{Na}+$ channel proteins: components of a vascular mechanosensor. Hypertension. 2004 Nov;44(5):643-8.

85 Jernigan NL, Drummond HA. Myogenic vasoconstriction in mouse renal interlobar arteries: role of endogenous beta and gammaENaC. Am J Physiol Renal Physiol. 2006 Dec; 291(6):F1184-91.

86 Day PW, Rasmussen SG, Parnot C, Fung JJ, Masood A, Kobilka TS, et al. A monoclonal antibody for $\mathrm{G}$ protein-coupled receptor crystallography. Nat Methods. 2007 Nov;4(11):927-9.

87 Hanson MA, Roth CB, Jo E, Griffith MT, Scott FL, Reinhart G, et al. Crystal structure of a lipid G protein-coupled receptor. Science. 2012 Feb 17;335(6070):851-5.

88 Simon MI, Strathmann MP, Gautam N. Diversity of $\mathrm{G}$ proteins in signal transduction. Science. 1991 May 10;252(5007):802-8.

89 Kontou P, Pavlopoulou A, Dimou N, Theodoropoulou M, Braliou G, Tsaousis G, et al. The human GPCR signal transduction network. Netw Model Anal Health Inform Bioinforma. 2021;10(1):3

90 Storch U, Mederos y Schnitzler M, Gudermann T. G protein-mediated stretch reception. Am J Physiol Heart Circ Physiol. 2012 Mar 15;302(6):H1241-9.
91 Mederos y Schnitzler M, Storch U, Meibers S, Nurwakagari P, Breit A, Essin K, et al. Gqcoupled receptors as mechanosensors mediating myogenic vasoconstriction. Embo J. 2008 Dec 3;27(23):3092-103

92 Kauffenstein G, Laher I, Matrougui K, Guérineau NC, Henrion D. Emerging role of G protein-coupled receptors in microvascular myogenic tone. Cardiovasc Res. 2012 Jul 15 95(2):223-32.

93 Nguyen KT, Frye SR, Eskin SG, Patterson C, Runge MS, McIntire LV. Cyclic strain in creases protease-activated receptor-1 expression in vascular smooth muscle cells. Hypertension. 2001 Nov;38(5):1038-43.

94 Kurpinski K, Park J, Thakar RG, Li S. Regulation of vascular smooth muscle cells and mesenchymal stem cells by mechanical strain. Mol Cell Biomech. 2006 Mar;3(1): 21-34.

95 Kona S, Chellamuthu P, Xu H, Hills SR, Nguyen KT. Effects of cyclic strain and growth factors on vascular smooth muscle cell responses. Open Biomed Eng J. 2009 Aug 31;3:28-38.

96 Wingler LM, Skiba MA, McMahon C, Staus DP, Kleinhenz ALW, Suomivuori CM, et al. Angiotensin and biased analogs induce structurally distinct active conformations within a GPCR. Science. 2020 Feb 21; 367(6480):888-92.

97 Pires PW, Ko EA, Pritchard HAT, Rudokas M, Yamasaki E, Earley S. The angiotensin II receptor type $1 \mathrm{~b}$ is the primary sensor of intraluminal pressure in cerebral artery smooth muscle cells. J Physiol. 2017 Jul 15; 595(14):4735-53

98 Schleifenbaum J, Kassmann M, Szijártó IA, Hercule HC, Tano JY, Weinert S, et al. Stretch-activation of angiotensin II type 1a receptors contributes to the myogenic response of mouse mesenteric and renal arteries. Circ Res. 2014 Jul 7;115(2):263-72.

99 Xie GX, Palmer PP. How regulators of G protein signaling achieve selective regulation. J Mol Biol. 2007 Feb 16;366(2):349-65.

100 Mederos YSM, Storch U, Gudermann T. Mechanosensitive $\mathrm{Gq} / 11$ protein-coupled receptors mediate myogenic vasoconstriction. Microcirculation. 2016 Nov;23(8): 621-5.

101 Meleka MM, Edwards AJ, Xia J, Dahlen SA, Mohanty I, Medcalf M, et al. Anti-hypertensive mechanisms of cyclic depsipeptide inhibitor ligands for $\mathrm{Gq} / 11$ class $\mathrm{G}$ proteins. Pharmacol Res. 2019 Mar;141:264-75.

102 Chennupati R, Wirth A, Favre J, Li R, Bonnavion R, Jin $\mathrm{YJ}$, et al. Myogenic vasoconstriction requires G12/G13 and LARG to maintain local and systemic vascular resistance. Elife. 2019 Sep 24;8.

103 Storch U, Blodow S, Gudermann T, Mederos Y Schnitzler M. Cysteinyl leukotriene 1 receptors as novel mechanosensors mediating myogenic tone together with angiotensin Il type 1 receptors-brief report. Arterioscler Thromb Vasc Biol. 2015 Jan;35(1):121-6. 
104 Kitamura N, Kaminuma O, Ohtomo T, Kiyokawa N, Kobayashi N, Suko M, et al. Evaluation of cysteinyl leukotriene-induced contraction of human cultured bronchial smooth muscle cells. Int Arch Allergy Immunol. 2009;149(Suppl 1):83-6.

105 Burnstock G, Ralevic V. Purinergic signaling and blood vessels in health and disease. Pharmacol Rev. 2014;66(1):102-92.

106 Nishimura A, Sunggip C, Tozaki-Saitoh H, Shimauchi T, Numaga-Tomita T, Hirano $\mathrm{K}$, et al. Purinergic P2Y6 receptors heterodimerize with angiotensin AT1 receptors to promote angiotensin II-induced hypertension. Sci Signal. 2016 Jan 19;9(411): ra7.

107 Bar I, Guns PJ, Metallo J, Cammarata D, Wilkin F, Boeynams JM, et al. Knockout mice reveal a role for P2Y6 receptor in macrophages, endothelial cells, and vascular smooth muscle cells. Mol Pharmacol. 2008 Sep;74(3):777-84.

108 Kauffenstein G, Tamareille S, Prunier F, Roy C, Ayer A, Toutain B, et al. Central role of P2Y6 UDP receptor in arteriolar myogenic tone. Arterioscler Thromb Vasc Biol. 2016 Aug;36(8):1598-606.

109 Liu S, Li Y, Zhang Z, Xie F, Xu Q, Huang X, et al. a1-Adrenergic receptors mediate combined signals initiated by mechanical stretch stress and norepinephrine leading to accelerated mouse vein graft atherosclerosis. J Vasc Surg. 2013 Jun;57(6):1645-3.

110 O'Brien PJ, Molino M, Kahn M, Brass LF. Protease activated receptors: theme and variations. Oncogene. 2001 Mar 26;20(13): 1570-81.

111 Heuberger DM, Schuepbach RA. Proteaseactivated receptors (PARs): mechanisms of action and potential therapeutic modulators in PAR-driven inflammatory diseases. Thromb J. 2019;17:4

112 Jones SM, Mann A, Conrad K, Saum K, Hall DE, McKinney LM, et al. PAR2 (proteaseactivated receptor 2) deficiency attenuates atherosclerosis in mice. Arterioscler Thromb Vasc Biol. 2018 Jun;38(6):1271-82.

113 Ruf W. Proteases, protease-activated receptors, and atherosclerosis. Arterioscler Thromb Vasc Biol. 2018 Jun;38(6):1252-4.

114 Garcia V, Gilani A, Shkolnik B, Pandey V, Zhang FF, Dakarapu R, et al. 20-HETE signals through G-protein-coupled receptor GPR75 (Gq) to affect vascular function and trigger hypertension. Circ Res. 2017 May 26; 120(11):1776-88.

$115 \mathrm{Xu} \mathrm{J}$, Mathur J, Vessières E, Hammack S, Nonomura K, Favre J, et al. GPR68 senses flow and is essential for vascular physiology. Cell. 2018 Apr 19;173(3):762-e16.

116 Klemm DJ, Watson PA, Frid MG, Dempsey EC, Schaack J, Colton LA, et al. cAMP response element-binding protein content is a molecular determinant of smooth muscle cell proliferation and migration. J Biol Chem. 2001 Dec 7;276(49): 46132-41.
117 Saxena H, Deshpande DA, Tiegs BC, Yan H, Battafarano RJ, Burrows WM, et al. The GPCR OGR1 (GPR68) mediates diverse signalling and contraction of airway smooth muscle in response to small reductions in extracellular pH. Br J Pharmacol. 2012 Jun; 166(3):981-90.

118 Ichimonji I, Tomura H, Mogi C, Sato K, Aoki H, Hisada T, et al. Extracellular acidification stimulates IL-6 production and $\mathrm{Ca}(2+)$ mobilization through proton-sensing OGR1 receptors in human airway smooth muscle cells. Am J Physiol Lung Cell Mol Physiol. 2010 Oct;299(4):L567-77.

119 Robinson DR, Wu YM, Lin SF. The protein tyrosine kinase family of the human genome. Oncogene. 2000 Nov 20;19(49):5548-57.

120 Trenker R, Jura N. Receptor tyrosine kinase activation: from the ligand perspective. Curr Opin Cell Biol. 2020 Apr;63:174-85.

121 Schlessinger J, Ullrich A. Growth factor signaling by receptor tyrosine kinases. Neuron. 1992 Sep;9(3):383-91.

122 Lemmon MA, Schlessinger J. Cell signaling by receptor tyrosine kinases. Cell. 2010 Jun 25;141(7):1117-34.

123 Pawson T. Protein modules and signalling networks. Nature. 1995 Feb 16;373(6515): 573-80.

124 Ren S, Yang G, He Y, Wang Y, Li Y, Chen Z. The conservation pattern of short linear motifs is highly correlated with the function of interacting protein domains. BMC genomics. 2008 Oct 1;9:452.

125 Meng Y, Pond MP, Roux B. Tyrosine kinase activation and conformational flexibility: lessons from Src-family tyrosine kinases. Acc Chem Res. 2017 May 16;50(5):1193201.

126 Zinkle A, Mohammadi M. A threshold model for receptor tyrosine kinase signaling specificity and cell fate determination. F1000Res. 2018;7.

127 Seo KW, Lee SJ, Kim YH, Bae JU, Park SY, Bae SS, et al. Mechanical stretch increases MMP-2 production in vascular smooth muscle cells via activation of PDGFR- $\beta /$ Akt signaling pathway. PLoS One. 2013;8(8): e70437.

$128 \mathrm{Hu} \mathrm{Y,} \mathrm{Böck} \mathrm{G,} \mathrm{Wick} \mathrm{G,} \mathrm{Xu} \mathrm{Q.} \mathrm{Activation} \mathrm{of}$ PDGF receptor alpha in vascular smooth muscle cells by mechanical stress. FASEB J. 1998 Sep;12(12):1135-42.

129 Tanabe Y, Saito M, Ueno A, Nakamura M, Takeishi K, Nakayama K. Mechanical stretch augments PDGF receptor beta expression and protein tyrosine phosphorylation in pulmonary artery tissue and smooth muscle cells. Mol Cell Biochem. 2000 Dec; 215(1-2):103-13.

130 Shimizu N, Yamamoto K, Obi S, Kumagaya S, Masumura T, Shimano Y, et al. Cyclic strain induces mouse embryonic stem cell differentiation into vascular smooth muscle cells by activating PDGF receptor beta. J Appl Physiol. 2008 Mar;104(3): 766-72.
131 Liu G, Hitomi H, Hosomi N, Lei B, Nakano $\mathrm{D}$, Deguchi K, et al. Mechanical stretch augments insulin-induced vascular smooth muscle cell proliferation by insulin-like growth factor-1 receptor. Exp Cell Res. 2011 Oct 15;317(17):2420-8.

132 Cheng J, Du J. Mechanical stretch simulates proliferation of venous smooth muscle cells through activation of the insulin-like growth factor-1 receptor. Arterioscler Thromb Vasc Biol. 2007 Aug;27(8):1744-51.

133 Liu G, Hitomi H, Hosomi N, Lei B, Pelisch N, Nakano D, et al. Mechanical stretch potentiates angiotensin II-induced proliferation in spontaneously hypertensive rat vascular smooth muscle cells. Hypertens Res. 2010 Dec;33(12):1250-7.

134 Iwasaki H, Eguchi S, Ueno H, Marumo F, Hirata Y. Mechanical stretch stimulates growth of vascular smooth muscle cells via epidermal growth factor receptor. Am J Physiol Heart Circ Physiol. 2000 Feb;278(2): H521-9.

135 Katsumi A, Orr AW, Tzima E, Schwartz MA. Integrins in mechanotransduction. J Biol Chem. 2004 Mar 26;279(13):120014.

136 Roca-Cusachs P, Iskratsch T, Sheetz MP. Finding the weakest link: exploring integrinmediated mechanical molecular pathways. J Cell Sci. 2012 Jul 1;125(Pt 13):3025-38.

137 Alenghat FJ, Ingber DE. Mechanotransduction: all signals point to cytoskeleton, matrix, and integrins. Sci STKE. 2002 Feb 12; 2002(119):pe6.

138 Schwartz MA. Integrins and extracellular matrix in mechanotransduction. Cold Spring Harb Perspect Biol. 2010 Dec;2(12):a005066.

139 Li Z, Lee H, Zhu C. Molecular mechanisms of mechanotransduction in integrin-mediated cell-matrix adhesion. Exp Cell Res. 2016 Nov 15;349(1):85-94.

140 Boudreau NJ, Jones PL. Extracellular matrix and integrin signalling: the shape of things to come. Biochem J. 1999 May 1;33(Pt 3): 481-8.

141 Ross TD, Coon BG, Yun S, Baeyens N, Tanaka $\mathrm{K}$, Ouyang $\mathrm{M}$, et al. Integrins in mechanotransduction. Curr Opin Cell Biol. 2013 Oct;25(5):613-8.

142 Mao X, Said R, Louis H, Max JP, Bourhim M, Challande P, et al. Cyclic stretch-induced thrombin generation by rat vascular smooth muscle cells is mediated by the integrin $a v \beta 3$ pathway. Cardiovasc Res. 2012 Dec 1;96(3): 513-23.

143 Byzova TV, Plow EF. Activation of alphaVbeta 3 on vascular cells controls recognition of prothrombin. J Cell Biol. 1998 Dec 28; 143(7):2081-92.

144 Pyle AL, Atkinson JB, Pozzi A, Reese J, Eckes $B$, Davidson JM, et al. Regulation of the atheroma-enriched protein, SPRR3, in vascular smooth muscle cells through cyclic strain is dependent on integrin alpha1beta1/collagen interaction. Am J Pathol. 2008 Nov;173(5): 1577-88. 
145 Balasubramanian L, Ahmed A, Lo CM, Sham JS, Yip KP. Integrin-mediated mechanotransduction in renal vascular smooth muscle cells: activation of calcium sparks. Am J Physiol Regul Integr Comp Physiol. 2007 Oct;293(4):R1586-94.

146 Rezaee M, Penta K, Quertermous T. Dell mediates VSMC adhesion, migration, and proliferation through interaction with integrin alpha(v)beta(3). Am J Physiol Heart Circ Physiol. 2002 May;282(5):H1924-32.

147 Song Y, Qin X, Wang H, Miao R, Zhang Y, Miao C, et al. Effects of integrin $\alpha 5 \beta 1$ on the proliferation and migration of human aortic vascular smooth muscle cells. Mol Med Rep. 2016 Feb;13(2):1147-55.

$148 \mathrm{Wu} \mathrm{J}$, Zhang Y, Yang P, Enkhjargal B, Manaenko A, Tang J, et al. Recombinant osteopontin stabilizes smooth muscle cell phenotype via integrin receptor/integrin-linked kinase/Rac-1 pathway after subarachnoid hemorrhage in rats. Stroke. 2016 May;47(5): 1319-27.

149 Li S, Van Den Diepstraten C, D’Souza SJ, Chan BM, Pickering JG. Vascular smooth muscle cells orchestrate the assembly of type I collagen via alpha2beta1 integrin, RhoA, and fibronectin polymerization. Am J Pathol. 2003 Sep;163(3):1045-56.

150 Gallant ND, Michael KE, García AJ. Cell adhesion strengthening: contributions of adhesive area, integrin binding, and focal adhesion assembly. Mol Biol Cell. 2005 Sep; 16(9):4329-40.

151 Guan JL. Role of focal adhesion kinase in integrin signaling. Int J Biochem Cell Biol. 1997 Aug;29(8-9):1085-96.

152 Humphries JD, Chastney MR, Askari JA, Humphries MJ. Signal transduction via integrin adhesion complexes. Curr Opin Cell Biol. 2019 Feb;56:14-21.

153 Morla AO, Mogford JE. Control of smooth muscle cell proliferation and phenotype by integrin signaling through focal adhesion kinase. Biochem Biophys Res Commun. 2000 May 27;272(1):298-302.

154 Murphy JM, Jeong K, Lim SS. FAK family kinases in vascular diseases. Int J Mol Sci. 2020 May 21;21(10).

155 Wu X, Bian F, Hu H, Zhu T, Li C, Zhou Q. Effects of Kindlin-2 on proliferation and migration of VSMC and integrin $\beta 1$ and $\beta 3$ activity via FAK-PI3K signaling pathway. PLoS One. 2020;15(6):e0225173.

156 He Y, Zou P, Lu Y, Jia D, Li X, Yang H, et al. Osteoprotegerin promotes intimal hyperplasia and contributes to in-stent restenosis: Role of an alphaVbeta3/FAK dependent YAP pathway. J Mol Cell Cardiol. 2020 Feb; 139:1-13.

157 Jia D, Zhu Q, Liu H, Zuo C, He Y, Chen G, et al. Osteoprotegerin disruption attenuates HySu-induced pulmonary hypertension through integrin $\alpha \mathrm{v} \beta 3 / \mathrm{FAK} / \mathrm{AKT}$ pathway suppression. Circ Cardiovasc Genet. 2017 Feb;10(1).

158 Tsai MS, Chiang MT, Tsai DL, Yang CW, Hou HS, Li YR, et al. Galectin-1 restricts vas- cular smooth muscle cell motility via modulating adhesion force and focal adhesion dynamics. Sci Rep. 2018 Jul 31;8(1):11497.

159 Chan KC, Ho HH, Lin MC, Yen CH, Huang $\mathrm{CN}$, Huang HP, et al. Mulberry water extracts inhibit atherosclerosis through suppression of the integrin-beta(3)/focal adhesion kinase complex and downregulation of nuclear factor kappaB signaling in vivo and in vitro. J Agri Food Chem. 2014 Oct 1; 62(39):9463-71.

160 Sun Z, Huang S, Li Z, Meininger GA. Zyxin is involved in regulation of mechanotransduction in arteriole smooth muscle cells. Front Physiol. 2012;3:472.

161 Dangers M, Kiyan J, Grote K, Schieffer B, Haller H, Dumler I. Mechanical stress modulates SOCS-1 expression in human vascular smooth muscle cells. J Vasc Res. 2010;47(5): 432-40.

162 Dwivedi A, Sala-Newby GB, George SJ. Regulation of cell-matrix contacts and betacatenin signaling in VSMC by integrinlinked kinase: implications for intimal thickening. Basic Res Cardiol. 2008 May;103(3): 244-56.

163 Chu YS, Thomas WA, Eder O, Pincet F, Perez E, Thiery JP, et al. Force measurements in E-cadherin-mediated cell doublets reveal rapid adhesion strengthened by actin cytoskeleton remodeling through $\mathrm{Rac}$ and Cdc42. J Cell Biol. 2004 Dec 20;167(6):118394.

164 Mege RM, Ishiyama N. Integration of cadherin adhesion and cytoskeleton at adherens junctions. Cold Spring Harb Perspect Biol. 2017 May 1;9(5).

165 Liu WF, Nelson CM, Tan JL, Chen CS. Cadherins, RhoA, and Rac1 are differentially required for stretch-mediated proliferation in endothelial versus smooth muscle cells. Circ Res. 2007 Aug 31;101(5):e44-52.

166 Row S, Liu Y, Alimperti S, Agarwal SK, Andreadis ST. Cadherin-11 is a novel regulator of extracellular matrix synthesis and tissue mechanics. J Cell Sci. 2016 Aug 1;129(15): 2950-61.

167 Alimperti S, You H, George T, Agarwal SK, Andreadis ST. Cadherin-11 regulates both mesenchymal stem cell differentiation into smooth muscle cells and the development of contractile function in vivo. J Cell Sci. 2014 Jun 15;127(Pt 12):2627-38.

168 Marastoni S, Ligresti G, Lorenzon E, Colombatti A, Mongiat M. Extracellular matrix: a matter of life and death. Connect Tissue Res. 2008;49(3):203-6.

169 Bressan GM, Daga-Gordini D, Colombatti A, Castellani I, Marigo V, Volpin D. Emilin, a component of elastic fibers preferentially located at the elastin-microfibrils interface. J Cell Biol. 1993 Apr;121(1):201-12.

170 Mongiat M, Mungiguerra G, Bot S, Mucignat MT, Giacomello E, Doliana R, et al. Selfassembly and supramolecular organization of EMILIN. J Biol Chem. 2000 Aug 18; 275(33):25471-80.
171 Colombatti A, Spessotto P, Doliana R, Mongiat M, Bressan GM, Esposito G. The EMILIN/multimerin family. Front Immunol. 2011;2:93.

172 Zanetti M, Braghetta P, Sabatelli P, Mura I, Doliana R, Colombatti A, et al. EMILIN-1 deficiency induces elastogenesis and vascular cell defects. Mol Cell Biol. 2004 Jan;24(2):638-50.

173 Zacchigna L, Vecchione C, Notte A, Cordenonsi M, Dupont S, Maretto S, et al. Emilin1 links TGF-beta maturation to blood pressure homeostasis. Cell. 2006 Mar 10;124(5):929-42.

174 Litteri G, Carnevale D, D'Urso A, Cifelli G, Braghetta P, Damato A, et al. Vascular smooth muscle Emilin-1 is a regulator of arteriolar myogenic response and blood pressure. Arterioscler Thromb Vasc Biol. 2012 Sep;32(9):2178-84.

175 Carnevale D, Facchinello N, Iodice D, Bizzotto D, Perrotta M, De Stefani D, et al. Loss of EMILIN-1 enhances arteriolar myogenic tone through TGF-beta (transforming growth factor-beta)-dependent transactivation of EGFR (epidermal growth factor receptor) and is relevant for hypertension in mice and humans. Arterioscler Thromb Vasc Biol. 2018 Oct;38(10):2484-97.

176 Massett MP, Bywaters BC, Gibbs HC, Trzeciakowski JP, Padgham S, Chen J, et al Loss of smooth muscle $\alpha$-actin effects on mechanosensing and cell-matrix adhesions. Exp Biol Med. 2020 Feb;245(4):374-84.

177 Patel VB, Wang Z, Fan D, Zhabyeyev P, Basu $\mathrm{R}$, Das SK, et al. Loss of p47phox subunit enhances susceptibility to biomechanical stress and heart failure because of dysregulation of cortactin and actin filaments. Circ Res. 2013 Jun 7;112(12):1542-56.

178 Langlois B, Belozertseva E, Parlakian A Bourhim M, Gao-Li J, Blanc J, et al. Publisher correction: vimentin knockout results in increased expression of sub-endothelial basement membrane components and carotid stiffness in mice. Sci Rep. 2018 Mar 6;8(1):4293.

179 Tang L, Dai F, Liu Y, Yu X, Huang C, Wang $\mathrm{Y}$, et al. RhoA/ROCK signaling regulates smooth muscle phenotypic modulation and vascular remodeling via the JNK pathway and vimentin cytoskeleton. Pharmacol Res. 2018 Jul;133:201-12.

180 Khatau SB, Hale CM, Stewart-Hutchinson PJ, Patel MS, Stewart CL, Searson PC, et al. A perinuclear actin cap regulates nuclear shape. Proc Natl Acad Sci USA. 2009 Nov 10; 106(45):19017-22.

181 Lovett DB, Shekhar N, Nickerson JA, Roux KJ, Lele TP. Modulation of nuclear shape by substrate rigidity. Cell Mol Bioeng. 2013 Jun $1 ; 6(2): 230-8$.

182 Hatch EM, Hetzer MW. Nuclear envelope rupture is induced by actin-based nucleus confinement. J Cell Biol. 2016 Oct 10;215(1): 27-36.

183 Gieni RS, Hendzel MJ. Mechanotransduction from the ECM to the genome: are the pieces now in place? J Cell Biochem. 2008 Aug 15;104(6): 1964-87. 
184 Starr DA. A nuclear-envelope bridge positions nuclei and moves chromosomes. J Cell Sci. 2009 Mar 1;122(Pt 5):577-86.

185 Beaudouin J, Gerlich D, Daigle N, Eils R, Ellenberg J. Nuclear envelope breakdown proceeds by microtubule-induced tearing of the lamina. Cell. 2002 Jan 11;108(1):83-96.

186 Salina D, Bodoor K, Eckley DM, Schroer TA, Rattner JB, Burke B. Cytoplasmic dynein as a facilitator of nuclear envelope breakdown. Cell. 2002 Jan 11;108(1):97-107.

187 Bonne G, Di Barletta MR, Varnous S, Bécane HM, Hammouda EH, Merlini L, et al. Mutations in the gene encoding lamin $\mathrm{A} / \mathrm{C}$ cause autosomal dominant Emery-Dreifuss muscular dystrophy. Nat Genet. 1999 Mar;21(3):285-8.

188 Qi YX, Yao QP, Huang K, Shi Q, Zhang P, Wang GL, et al. Nuclear envelope proteins modulate proliferation of vascular smooth muscle cells during cyclic stretch application. Proc Natl Acad Sci USA. 2016 May 10; 113(19):5293-8.

189 Sward K, Mita M, Wilson DP, Deng JT, Susnjar M, Walsh MP. The role of RhoA and Rho-associated kinase in vascular smooth muscle contraction. Curr Hypertens Rep. 2003 Feb;5(1):66-72.

190 Wang Y, Zheng XR, Riddick N, Bryden M, Baur W, Zhang X, et al. ROCK isoform regulation of myosin phosphatase and contractility in vascular smooth muscle cells. Circ Res. 2009 Feb 27;104(4):531-40.

191 Kato T, Hashikabe H, Iwata C, Akimoto K, Hattori Y. Statin blocks Rho/Rho-kinase signalling and disrupts the actin cytoskeleton: relationship to enhancement of LPS-mediated nitric oxide synthesis in vascular smooth muscle cells. Biochim Biophys Acta. 2004 Aug 4;1689(3):267-72.

192 Kang H, Liu J, Sun A, Liu X, Fan Y, Deng X. Vascular smooth muscle cell glycocalyx mediates shear stress-induced contractile responses via a Rho kinase (ROCK)-myosin light chain phosphatase (MLCP) pathway. Sci Rep. 2017 Feb 13;7:42092.

193 Ogita H, Kunimoto S, Kamioka Y, Sawa H, Masuda M, Mochizuki N. EphA4-mediated Rho activation via Vsm-RhoGEF expressed specifically in vascular smooth muscle cells. Circ Res. 2003 Jul 11;93(1):23-31.

194 Neves KB, Harvey AP, Moreton F, Montezano AC, Rios FJ, Alves-Lopes R, et al. ER stress and Rho kinase activation underlie the vasculopathy of CADASIL. JCI insight. 2019 Dec 5;4(23).

195 Chen NX, Chen X, O’Neill KD, Atkinson SJ, Moe SM. RhoA/Rho kinase (ROCK) alters fetuin-A uptake and regulates calcification in bovine vascular smooth muscle cells (BVSMC). Am J Physiol Renal Physiol. 2010 Sep;299(3):F674-80.

196 Weiss S, Frischknecht K, Greutert H, Payeli S, Steffel J, Lüscher TF, et al. Different migration of vascular smooth muscle cells from human coronary artery bypass vessels. Role of Rho/ROCK pathway. J Vasc Res. 2007; 44(2):149-56.
197 Muslin AJ. MAPK signalling in cardiovascular health and disease: molecular mechanisms and therapeutic targets. Clin Sci (Lond). 2008 Oct;115(7):203-18.

198 Wang Y. Mitogen-activated protein kinases in heart development and diseases. Circulation. 2007 Sep 18;116(12):1413-23.

199 Xu Q, Liu Y, Gorospe M, Udelsman R, Holbrook NJ. Acute hypertension activates mitogen-activated protein kinases in arterial wall. J Clin Invest. 1996 Jan 15;97(2):50814.

200 Li C, Hu Y, Mayr M, Xu Q. Cyclic strain stress-induced mitogen-activated protein kinase (MAPK) phosphatase 1 expression in vascular smooth muscle cells is regulated by Ras/Rac-MAPK pathways. J Biol Chem. 1999 Sep 3;274(36):25273-80.

201 Schaeffer C, Vandroux D, Thomassin L, Athias P, Rochette L, Connat JL. Calcitonin gene-related peptide partly protects cultured smooth muscle cells from apoptosis induced by an oxidative stress via activation of ERK1/2 MAPK. Biochim Biophys Acta. 2003 Dec 7;1643(1-3):65-73.

202 Zhang L, Zhang Y, Wu Y, Yu J, Zhang Y, Zeng $\mathrm{F}$, et al. Role of the balance of Akt and MAPK pathways in the exercise-regulated phenotype switching in spontaneously hypertensive rats. Int J Mol Sci. 2019 Nov 13;20(22).

203 Wang L, Deng L, Lin N, Shi Y, Chen J, Zhou $\mathrm{Y}$, et al. Berberine inhibits proliferation and apoptosis of vascular smooth muscle cells induced by mechanical stretch via the PDI/ ERS and MAPK pathways. Life Sci. 2020 Oct 15;259:118253.

204 Dupont S, Morsut L, Aragona M, Enzo E, Giulitti S, Cordenonsi M, et al. Role of YAP/ TAZ in mechanotransduction. Nature. 2011 Jun 8;474(7350):179-83.

205 Hao J, Zhang Y, Wang Y, Ye R, Qiu J, Zhao $Z$, et al. Role of extracellular matrix and YAP/TAZ in cell fate determination. Cell Signal. 2014 Feb;26(2):186-91.

206 Gao J, He L, Zhou L, Jing Y, Wang F, Shi Y, et al. Mechanical force regulation of YAP by F-actin and GPCR revealed by super-resolution imaging. Nanoscale. 2020 Jan 28;12(4): 2703-14.

207 Hilman D, Gat U. The evolutionary history of YAP and the hippo/YAP pathway. Mol Biol Evol. 2011 Aug;28(8):2403-17.

208 Zhao B, Tumaneng K, Guan KL. The Hippo pathway in organ size control, tissue regeneration and stem cell self-renewal. Nat Cell Biol. 2011 Aug 1;13(8):877-83.

209 Montagner M, Dupont S. Mechanical forces as determinants of disseminated metastatic cell fate. Cells. 2020 Jan 19;9(1).

210 Piccolo S, Dupont S, Cordenonsi M. The biology of YAP/TAZ: hippo signaling and beyond. Physiol Rev. 2014 Oct;94(4):1287312.

211 Mohri Z, Del Rio Hernandez A, Krams R. The emerging role of YAP/TAZ in mechanotransduction. J Thorac Dis. 2017 May; 9(5):E507-E09.
212 Totaro A, Panciera T, Piccolo S. YAP/TAZ upstream signals and downstream responses. Nat Cell Biol. 2018 Aug;20(8): 888-99.

213 Dobrokhotov O, Samsonov M, Sokabe M, Hirata H. Mechanoregulation and pathology of YAP/TAZ via Hippo and non-Hippo mechanisms. Clin Transl Med. 2018 Aug 13; $7(1): 23$.

214 Seo J, Kim J. Regulation of Hippo signaling by actin remodeling. BMB Rep. 2018 Mar; 51(3):151-6.

215 Zhang J, Zhou Y, Tang PMK, Cheng ASL, $\mathrm{Yu}$ J, To KF, et al. Mechanotransduction and cytoskeleton remodeling shaping YAP1 in gastric tumorigenesis. Int J Mol Sci. 2019 Mar 29;20(7).

216 Yu FX, Zhao B, Panupinthu N, Jewell JL, Lian I, Wang LH, et al. Regulation of the Hippo-YAP pathway by G-protein-coupled receptor signaling. Cell. 2012 Aug 17;150(4): 780-91.

217 Dasgupta I, McCollum D. Control of cellular responses to mechanical cues through YAP/ TAZ regulation. J Biol Chem. 2019 Nov 15; 294(46):17693-706.

218 Pocaterra A, Santinon G, Romani P, Brian I, Dimitracopoulos A, Ghisleni A, et al. F-actin dynamics regulates mammalian organ growth and cell fate maintenance. J Hepatol. 2019 Jul;71(1):130-42.

219 He J, Bao Q, Yan M, Liang J, Zhu Y, Wang $\mathrm{C}$, et al. The role of Hippo/yes-associated protein signalling in vascular remodelling associated with cardiovascular disease. $\mathrm{Br} \mathrm{J}$ Pharmacol. 2018 Apr;175(8):1354-61.

220 Wang KC, Yeh YT, Nguyen P, Limqueco E, Lopez J, Thorossian S, et al. Flow-dependent YAP/TAZ activities regulate endothelial phenotypes and atherosclerosis. Proc Natl Acad Sci USA. 2016 Oct 11;113(41):1152530.

221 Wang L, Luo JY, Li B, Tian XY, Chen LJ, Huang $Y$, et al. Integrin-YAP/TAZ-JNK cascade mediates atheroprotective effect of unidirectional shear flow. Nature. 2016 Dec 22; 540(7634):579-82.

222 Niu N, Xu S, Xu Y, Little PJ, Jin ZG. Targeting mechanosensitive transcription factors in atherosclerosis. Trends Pharmacol Sci. 2019 Apr;40(4):253-66.

223 Bondareva O, Tsaryk R, Bojovic V, Odenthal-Schnittler M, Siekmann AF, Schnittler HJ. Identification of atheroprone shear stress responsive regulatory elements in endothelial cells. Cardiovasc Res. 2019 Aug 1; 115(10):1487-99.

224 Li B, He J, Lv H, Liu Y, Lv X, Zhang C, et al. c-Abl regulates YAPY357 phosphorylation to activate endothelial atherogenic responses to disturbed flow. J Clin Invest. 2019 Mar 1;129(3):1167-79.

225 Thenappan T, Chan SY, Weir EK. Role of extracellular matrix in the pathogenesis of pulmonary arterial hypertension. Am J Physiol Heart Circ Physiol. 2018 Nov 1; 315(5):H1322-H31. 
226 Bertero T, Cottrill KA, Lu Y, Haeger CM, Dieffenbach P, Annis S, et al. Matrix remodeling promotes pulmonary hypertension through feedback mechanoactivation of the YAP/TAZ-miR-130/301 circuit. Cell Rep. 2015 Nov 3;13(5):1016-32.

227 Sun M, Sun Y, Feng Z, Kang X, Yang W, Wang Y, et al. New insights into the Hippo/ YAP pathway in idiopathic pulmonary fibrosis. Pharmacol Res. 2021 Jul; 169: 105635.

228 Hooglugt A, van der Stoel MM, Boon RA, Huveneers S. Endothelial YAP/TAZ signaling in angiogenesis and tumor vasculature. Front Oncol. 2020;10:612802.

229 van der Stoel M, Schimmel L, Nawaz K, van Stalborch AM, de Haan A, Klaus-Bergmann A, et al. DLC1 is a direct target of activated YAP/TAZ that drives collective migration and sprouting angiogenesis. J Cell Sci. 2020 Feb 12;133(3):133.

230 Ruiter MS, Pesce M. Mechanotransduction in coronary vein graft disease. Front Cardiovasc Med. 2018;5:20.

231 Asaoka Y, Nishina H, Furutani-Seiki M. YAP is essential for 3D organogenesis withstanding gravity. Dev Growth Differ. 2017 Jan;59(1):52-8.

232 Virdi JK, Pethe P. Biomaterials regulate mechanosensors YAP/TAZ in stem cell growth and differentiation. J Tissue Eng Regen Med. 2021 Apr;18(2):199-215.

233 Wang Y, Cao W, Cui J, Yu Y, Zhao Y, Shi J, et al. Arterial wall stress induces phenotypic switching of arterial smooth muscle cells in vascular remodeling by activating the YAP/ TAZ signaling pathway. Cell Physiol Biochem. 2018;51(2):842-53.

234 Li H, Jiang W, Ren W, Guo D, Guo J, Wang $\mathrm{X}$, et al. Downregulation of the yes-associated protein is associated with extracellular matrix disorders in ascending aortic aneurysms. Stem Cells Int. 2016;2016:6786184.

235 Yamashiro Y, Thang BQ, Ramirez K, Shin SJ, Kohata T, Ohata S, et al. Matrix mechanotransduction mediated by thrombospondin-1/integrin/YAP in the vascular remodeling. Proc Natl Acad Sci USA. 2020 May 5; 117(18):9896-905.

236 Feng X, Liu P, Zhou X, Li MT, Li FL, Wang $\mathrm{Z}$, et al. Thromboxane A2 activates YAP/ TAZ protein to induce vascular smooth muscle cell proliferation and migration. J Biol Chem. 2016 Sep 2;291(36):18947-58.

237 Kimura TE, Duggirala A, Smith MC, White S, Sala-Newby GB, Newby AC, et al. The Hippo pathway mediates inhibition of vascular smooth muscle cell proliferation by cAMP. J Mol Cell Cardiol. 2016 Jan;90:110

238 Wang X, Hu G, Gao X, Wang Y, Zhang W, Harmon EY, et al. The induction of yes-associated protein expression after arterial injury is crucial for smooth muscle phenotypic modulation and neointima formation. Arterioscler Thromb Vasc Biol. 2012 Nov; 32(11):2662-9.
239 Levi N, Papismadov N, Solomonov I, Sagi I, Krizhanovsky V. The ECM path of senescence in aging: components and modifiers. FEBS J. 2020 Jul;287(13):2636-46.

240 Schlie-Wolter S, Ngezahayo A, Chichkov BN. The selective role of ECM components on cell adhesion, morphology, proliferation and communication in vitro. Exp Cell Res. 2013 Jun 10;319(10):1553-61.

241 Chaudhuri O, Cooper-White J, Janmey PA, Mooney DJ, Shenoy VB. Effects of extracellular matrix viscoelasticity on cellular behaviour. Nature. 2020 Aug;584(7822):535-46.

242 Lehoux S, Castier Y, Tedgui A. Molecular mechanisms of the vascular responses to haemodynamic forces. J Intern Med. 2006 Apr;259(4):381-92.

243 Chang CJ, Huang CC, Chen PR, Lai YJ. Remodeling matrix synthesis in a rat model of aortocaval fistula and the cyclic stretch: impaction in pulmonary arterial hypertensioncongenital heart disease. Int J Mol Sci. 2020 Jun 30;21(13):21.

244 Sumpio BE, Banes AJ, Link WG, Johnson G Jr. Enhanced collagen production by smooth muscle cells during repetitive mechanical stretching. Arch Surg. 1988 Oct;123(10): 1233-6.

245 Wanjare M, Agarwal N, Gerecht S. Biomechanical strain induces elastin and collagen production in human pluripotent stem cellderived vascular smooth muscle cells. Am J Physiol Cell Physiol. 2015 Aug 15;309(4): C271-81.

246 Feng Y, Yang JH, Huang H, Kennedy SP, Turi TG, Thompson JF, et al. Transcriptional profile of mechanically induced genes in human vascular smooth muscle cells. Circ Res. 1999 Dec 3-17;85(12):1118-23.

247 Stanley AG, Patel H, Knight AL, Williams B. Mechanical strain-induced human vascular matrix synthesis: the role of angiotensin II. J Renin Angiotensin Aldosterone Syst. 2000 Mar;1(1):32-5.

248 Niklason LE, Gao J, Abbott WM, Hirschi KK, Houser S, Marini R, et al. Functional arteries grown in vitro. Science. 1999 Apr 16; 284(5413):489-93.

249 Isenberg BC, Tranquillo RT. Long-term cyclic distention enhances the mechanical properties of collagen-based media-equivalents. Ann Biomed Eng. 2003 Sep;31(8):93749.

250 Levesque L, Loy C, Laine A, Drouin B, Chevallier $\mathrm{P}$, Mantovani $\mathrm{D}$. Incrementing the frequency of dynamic strain on SMC-cellularised collagen-based scaffolds affects extracellular matrix remodeling and mechanical properties. ACS Biomat Sci Engineer. 2018 Nov 12;4(11):3759-67.

251 Chen W, Yang J, Liao W, Zhou J, Zheng J, $\mathrm{Wu} \mathrm{Y}$, et al. In vitro remodeling and structural characterization of degradable polymer scaffold-based tissue-engineered vascular grafts using optical coherence tomography. Cell Tissue Res. 2017 Dec;370(3): 417-26.
252 Chen W, Liu S, Yang J, Wu Y, Ma W, Lin Z. Nondestructive monitoring of degradable scaffold-based tissue-engineered blood vessel development using optical coherence tomography. J Vis Exp. 2018 Oct 3(140).

253 Leung DY, Glagov S, Mathews MB. Cyclic stretching stimulates synthesis of matrix components by arterial smooth muscle cells in vitro. Science. 1976 Feb 6;191(4226):475-7.

254 Li L, Chaikof EL. Mechanical stress regulates syndecan-4 expression and redistribution in vascular smooth muscle cells. Arterioscler Thromb Vasc Biol. 2002 Jan;22(1): 61-8.

$255 \mathrm{He}$ Q, Lin Y, Liao B, Zhou L, Ai J, Jin X, et al. The role of interleukin-6/interleukin-6 receptor signaling in the mechanical stress-induced extracellular matrix remodelling of bladder smooth muscle. Arch Biochem Biophys. 2020 Nov 12:108674.

256 Asanuma K, Magid R, Johnson C, Nerem $\mathrm{RM}$, Galis ZS. Uniaxial strain upregulates matrix-degrading enzymes produced by human vascular smooth muscle cells. Am Physiol Heart Circ Physiol. 2003 May; 284(5):H1778-84.

257 Grote K, Flach I, Luchtefeld M, Akin E, Holland SM, Drexler $\mathrm{H}$, et al. Mechanical stretch enhances mRNA expression and proenzyme release of matrix metalloproteinase-2 (MMP-2) via NAD(P)H oxidase-derived reactive oxygen species. Circ Res. 2003 Jun 13; 92(11):e80-6.

258 Raffetto JD, Qiao X, Koledova VV, Khalil RA. Prolonged increases in vein wall tension increase matrix metalloproteinases and decrease constriction in rat vena cava: potential implications in varicose veins. J Vasc Surg. 2008 Aug;48(2):447-56.

259 Lee RT, Huang H. Mechanotransduction and arterial smooth muscle cells: new insight into hypertension and atherosclerosis. Ann Med. 2000 May;32(4):233-5.

260 DiRaimondo TR, Klöck C, Warburton R, Herrera Z, Penumatsa K, Toksoz D, et al. Elevated transglutaminase 2 activity is associated with hypoxia-induced experimental pulmonary hypertension in mice. ACS Chem Biol. 2014 Jan 17;9(1):266-75.

261 Alves-Lopes R, Neves KB, Anagnostopoulou A, Rios FJ, Lacchini S, Montezano AC, et al. Crosstalk between vascular redox and calcium signaling in hypertension involves TRPM2 (transient receptor potential melastatin 2) cation channel. Hypertension. 2020 Jan;75(1):139-49.

262 Furmanik M, Chatrou M, van Gorp R, Akbulut A, Willems B, Schmidt H, et al. Reactive oxygen-forming Nox5 links vascular smooth muscle cell phenotypic switching and extracellular vesicle-mediated vascular calcification. Circ Res. 2020 Sep 11;127(7): 911-27.

263 Toth A, Balogh E, Jeney V. Regulation of vascular calcification by reactive oxygen species. Antioxidants. 2020 Oct 8;9(10). 
264 Zhang L, Xu Z, Wu Y, Liao J, Zeng F, Shi L. Akt/eNOS and MAPK signaling pathways mediated the phenotypic switching of thoracic aorta vascular smooth muscle cells in aging/hypertensive rats. Physiol Res. 2018 Aug 16;67(4):543-53.

265 Criqui $\mathrm{MH}$, Aboyans V. Epidemiology of peripheral artery disease. Circ Res. $2015 \mathrm{Apr}$ 24;116(9):1509-26.

266 RDL. Engineering vessels as good as new? JACC Basic to translational science. 2018 Feb;3(1):119-21.

267 Akoh JA, Patel N. Infection of hemodialysis arteriovenous grafts. J Vasc Access. 2010 Apr;11(2):155-8.

268 Conte MS. Critical appraisal of surgical revascularization for critical limb ischemia. J Vasc Surg. 2013 Feb;57(2 Suppl 1):8S-13S.

269 Harskamp RE, Lopes RD, Baisden CE, de Winter RJ, Alexander JH. Saphenous vein graft failure after coronary artery bypass surgery: pathophysiology, management, and future directions. Ann Surg. 2013 May; 257(5):824-33.

270 Kunlin J. Long vein transplantation in treatment of ischemia caused by arteritis. Rev Chir. 1951 Jul;70(7-8):206-35.
271 Jackson MR, Belott TP, Dickason T, Kaiser WJ, Modrall JG, Valentine RJ, et al. The consequences of a failed femoropopliteal bypass grafting: comparison of saphenous vein and PTFE grafts. J Vasc Surg. 2000 Sep;32(3): 498-5.

272 Goins A, Webb AR, Allen JB. Multi-layer approaches to scaffold-based small diameter vessel engineering: a review. Mater Sci Eng C Mater Biol Appl. 2019 Apr;97:896-912.

273 Niklason LE, Lawson JH. Bioengineered human blood vessels. Science. 2020 Oct 9; 370(6513):370.

274 Huang AH, Niklason LE. Engineering of arteries in vitro. Cell Mol Life Sci. 2014 Jun; 71(11):2103-18

275 Kirkton RD, Santiago-Maysonet M, Lawson JH, Tente WE, Dahl SLM, Niklason LE, et al. Bioengineered human acellular vessels recellularize and evolve into living blood vessels after human implantation. Sci Transl Med. 2019 Mar 27;11(485):11.

276 Jeong SI, Kwon JH, Lim JI, Cho SW, Jung Y, Sung WJ, et al. Mechano-active tissue engineering of vascular smooth muscle using pulsatile perfusion bioreactors and elastic PLCL scaffolds. Biomaterials. 2005 Apr; 26(12):1405-11.
277 Luo J, Qin L, Zhao L, Gui L, Ellis MW, Huang Y, et al. Tissue-engineered vascular grafts with advanced mechanical strength from human iPSCs. Cell Stem Cell. $2020 \mathrm{Feb}$ 6;26(2):251-e8

278 Stegemann JP, Nerem RM. Phenotype modulation in vascular tissue engineering using biochemical and mechanical stimulation. Ann Biomed Eng. 2003 Apr;31(4):391-402.

279 Wen Z, Zhou H, Zhou J, Chen W, Wu Y, Lin Z. Quantitative evaluation of mechanical stimulation for tissue-engineered blood vessels. Tissue Eng Part C Methods. 2021 May; 27(5):337-47.

280 Chen ML, Ruberti JW, Nguyen TD. Increased stiffness of collagen fibrils following cyclic tensile loading. J Mech Behav Biomed Mater. 2018 Jun;82:345-54.

281 Haga JH, Li YS, Chien S. Molecular basis of the effects of mechanical stretch on vascular smooth muscle cells. J Biomech. 2007;40(5): 947-60. 